\title{
The climate of a retrograde rotating Earth
}

\author{
Uwe Mikolajewicz $^{1}$, Florian Ziemen ${ }^{1}$, Guido Cioni ${ }^{1,2}$, Martin Claussen $^{1,3}$, Klaus Fraedrich ${ }^{1,3}$, \\ Marvin Heidkamp ${ }^{1,2}$, Cathy Hohenegger ${ }^{1}$, Diego Jimenez de la Cuesta ${ }^{1,2}$, Marie-Luise Kapsch ${ }^{1}$, \\ Alexander Lemburg ${ }^{1,2}$, Thorsten Mauritsen ${ }^{1}$, Katharina Meraner ${ }^{1}$, Niklas Röber ${ }^{4}$, Hauke Schmidt ${ }^{1}$, \\ Katharina D. Six ${ }^{1}$, Irene Stemmler ${ }^{1}$, Talia Tamarin-Brodsky ${ }^{5}$, Alexander Winkler ${ }^{1,2}$, Xiuhua $\mathrm{Zhu}^{3}$, and \\ Bjorn Stevens ${ }^{1}$ \\ ${ }^{1}$ Max Planck Institute for Meteorology, Bundesstr. 53, Hamburg, Germany \\ ${ }^{2}$ International Max Planck Research School on Earth System \\ Modeling, Bundesstr. 53, Hamburg, Germany \\ ${ }^{3}$ Universität Hamburg, Meteorologisches Institut, Bundesstr. 55, Hamburg, Germany \\ ${ }^{4}$ Deutsches Klimarechenzentrum, Bundesstr. 45a, Hamburg, Germany \\ ${ }^{5}$ Department of Meteorology, University of Reading, Reading, UK \\ Correspondence: Uwe Mikolajewicz (uwe.mikolajewicz@mpimet.mpg.de) \\ Received: 15 May 2018 - Discussion started: 6 June 2018 \\ Revised: 6 September 2018 - Accepted: 26 September 2018 - Published: 12 October 2018
}

Abstract. To enhance understanding of Earth's climate, numerical experiments are performed contrasting a retrograde and prograde rotating Earth using the Max Planck Institute Earth system model. The experiments show that the sense of rotation has relatively little impact on the globally and zonally averaged energy budgets but leads to large shifts in continental climates, patterns of precipitation, and regions of deep water formation.

Changes in the zonal asymmetries of the continental climates are expected given ideas developed more than a hundred years ago. Unexpected was, however, the switch in the character of the European-African climate with that of the Americas, with a drying of the former and a greening of the latter. Also unexpected was a shift in the storm track activity from the oceans to the land in the Northern Hemisphere. The different patterns of storms and changes in the direction of the trades influence fresh water transport, which may underpin the change of the role of the North Atlantic and the Pacific in terms of deep water formation, overturning and northward oceanic heat transport. These changes greatly influence northern hemispheric climate and atmospheric heat transport by eddies in ways that appear energetically consistent with a southward shift of the zonally and annually averaged tropical rain bands. Differences between the zonally averaged energy budget and the rain band shifts leave the door open, however, for an important role for stationary eddies in determining the position of tropical rains. Changes in ocean biogeochemistry largely follow shifts in ocean circulation, but the emergence of a "super" oxygen minimum zone in the Indian Ocean is not expected. The upwelling of phosphate-enriched and nitratedepleted water provokes a dominance of cyanobacteria over bulk phytoplankton over vast areas - a phenomenon not observed in the prograde model.

What would the climate of Earth look like if it would rotate in the reversed (retrograde) direction? Which of the characteristic climate patterns in the ocean, atmosphere, or land that are observed in a present-day climate are the result of the direction of Earth's rotation? Is, for example, the structure of the oceanic meridional overturning circulation (MOC) a consequence of the interplay of basin location and rotation direction? In experiments with the Max Planck Institute Earth system model (MPI-ESM), we investigate the effects of a retrograde rotation in all aspects of the climate system.

The expected consequences of a retrograde rotation are reversals of the zonal wind and ocean circulation patterns. These changes are associated with major shifts in the temperature and precipitation patterns. For example, the temperature gradient between Europe and eastern Siberia is reversed, and the Sahara greens, while large parts of the Americas become deserts. Interestingly, the Intertropical Convergence Zone (ITCZ) shifts southward and 
the modeled double ITCZ in the Pacific changes to a single ITCZ, a result of zonal asymmetries in the structure of the tropical circulation.

One of the most prominent non-trivial effects of a retrograde rotation is a collapse of the Atlantic MOC, while a strong overturning cell emerges in the Pacific. This clearly shows that the position of the MOC is not controlled by the sizes of the basins or by mountain chains splitting the continents in unequal runoff basins but by the location of the basins relative to the dominant wind directions. As a consequence of the changes in the ocean circulation, a "super" oxygen minimum zone develops in the Indian Ocean leading to upwelling of phosphate-enriched and nitrate-depleted water. These conditions provoke a dominance of cyanobacteria over bulk phytoplankton over vast areas, a phenomenon not observed in the prograde model.

\section{Introduction}

When being introduced to Earth's climate, after learning about how quantities such as the latitude or elevation influence the climate of a region, schoolchildren learn about the zonal asymmetries in patterns of weather. A common exercise in this context is to compare and contrast the climate of a city on Europe's Atlantic coast with one at a similar latitude and elevation on the Atlantic coast of North America. In the midlatitudes, the climate of the west coast is usually more maritime and milder than on the east coast. In the subtropics, the climate of the west coast is drier and more Mediterranean (winter rains) than on the east coast, where seasonality is more extreme, with more monsoonal (summer rains) patterns of precipitation.

Alexander von Humboldt (1817) was the first to document this basic asymmetry in continental climate. His zero-degree annual averaged isotherm passed through Labrador $\left(54^{\circ} \mathrm{N}\right)$ on the western, and Lapland $\left(68^{\circ} \mathrm{N}\right)$ on the eastern boundary of the Atlantic Ocean (Munzar, 2012). These ideas were later codified by Wladimir Köppen, who - a century later - formalized his concept of climate zones (Köppen, 1923). Köppen designated northwestern Europe as an oceanic temperate climate $(\mathrm{Cfb})$, while at the same latitude on the eastern coast of North America, or Asia, the designation is that of subarctic (Dfc).

As Humboldt understood, the weather is only the proximate cause for this asymmetry; ultimately, it is imparted by the lay and composition of the land and the sense of Earth's rotation. Winds in the midlatitudes prevail from the west the westerlies. In the tropics, easterlies dominate. Likewise, warm western boundary currents, like the Gulf Stream in the North Atlantic or the Kuroshio in the North Pacific, develop along the eastern continental boundaries, drawing tropical waters northward before detaching from the coasts so that their seaward extensions or drifts help define the boundary between the subtropical and subpolar gyres. Their counterparts, the eastern boundary currents, flow along the opposite continental margin and advect colder subpolar waters equatorward. These cold currents are amplified by similarly flowing air currents, whose equatorward stress drives upwelling, which brings cold and nutrient-rich waters from depth to the surface, giving rise to their exceptional biological productivity. A famous, and fittingly named, example is the Humboldt Current, which flows northward along the Chilean and Peruvian coast.

Contemporary scholars still debate the relative role of the winds and the currents in shaping the asymmetries in the zonal climate. Models that neglect zonal asymmetries associated with ocean currents see little change in the asymmetric continental climates, suggesting that zonal asymmetries in the climate can be explained to result from the land's influence on the atmospheric circulation (Seager et al., 2002). Yet more idealized simulations (Kaspi and Schneider, 2011) demonstrate that a simple heat flux anomaly - similar to that which would be caused by the atmosphere flowing from a cold continent over a warmer ocean - is sufficient to set the asymmetry in the winds from which zonal asymmetries in near-surface air temperatures follow. In contrast to the vast literature concerned with the meridional extent of the monsoon, or the timing of its onset, the question as to what factors influence zonal asymmetries in the locations of monsoons and deserts (Rodwell and Hoskins, 1996) has attracted much less attention.

It seems indisputable that zonal asymmetries in the distribution of the land surface combined with the sense of planetary rotation provide the ultimate reason for asymmetries in Earth's zonal climate. More disputable, and hence more interesting, is to what extent these asymmetries influence the structure of Earth's zonally averaged climate. For example, why is the zonally averaged Intertropical Convergence Zone (ITCZ) mostly north of the Equator? Is - as some studies argue (Wallace et al., 1989; Philander et al., 1996) - the reason primarily related to zonal asymmetries in how continental boundaries align with prevailing wind systems? Or is its preference for the Northern Hemisphere a consequence of hemispheric asymmetries in the zonally averaged energy budget (Chiang et al., 2003; Kang et al., 2008)? Even if the hemispheric asymmetries in the heat budget are important, this raises the question as to their origin. Is it from hemispheric asymmetries in the distribution of land masses or from asymmetries in how the ocean transports heat (which might be more related to zonal asymmetries in the structure of ocean basins and their effect on deep water formation)? 
The global ocean conveyer belt (Broecker, 1991), with meridional overturning in the North Atlantic fueling a deep western boundary current that winds through the southern ocean, around Africa and into the Indian Ocean and North Pacific where waters again upwell, is a profound example of a hemispheric asymmetry that might ultimately result from zonal asymmetries in the climate system. The drivers of the conveyor belt are still inadequately understood. Though it is clear that the salt advection feedback suggested by Stommel (1961) stabilizes the current mode of overturning, it also creates the potential for arresting the Atlantic overturning, which thus implies multiple equilibria of the thermohaline circulation. But why is deep water not formed in the North Pacific? Two main mechanisms have been proposed (Warren, 1983), both invoking the role of zonal asymmetries. One is that the net freshwater gain in the Pacific (and the corresponding net freshwater loss in the Atlantic) leads to saltier subpolar water in the Atlantic and rather fresh water in the subpolar North Pacific, thus stabilizing the fresh Pacific relative to the salty Atlantic (Broecker, 1997). Another idea is that the limited northward extension of the Pacific limits the cooling in the northernmost parts of the Pacific basin. In contrast, the Atlantic extends all the way into the Arctic allowing the surface water to be cooled down to the freezing point.

For many of the above questions, changing the direction of rotation of the Earth thus presents an easy way to obtain a completely different climate, while maintaining the familiar configuration of the continents and oceans. In the new climate, changes in wind direction lead to changes in ocean circulation, precipitation patterns, and storm track locations in ways that inform our understanding of hemispheric and longitudinal asymmetries of the present climate system, such as the position of the tropical rain bands, or structure of the storm tracks. Two studies (Smith et al., 2008; Kamphuis et al., 2011) have explored the consequences of a retrograde rotation of the Earth with ocean circulation questions in mind. But even for these more-limited-in-scope studies, the authors come to quite different findings. Smith et al. (2008) found an inverse conveyor belt circulation with strong deep water formation in the North Pacific in a simulation with the climate model FAMOUS (Smith, 2012). Using another model, Kamphuis et al. (2011), meanwhile, found that deep water formation in the North Atlantic weakened in their simulations, and intensified intermediate water formation became evident in the North Pacific. This study did not, however, show evidence of a complete reversal in the role of the subpolar North Atlantic and Pacific for deep water formation, leading to the conclusion that an altered net freshwater flux is not sufficient to obtain the reversal, but that the continental geometry is crucial for the pattern of the overturning circulation.

The two aforementioned studies, as noted, focus on the effect of the direction of the Earth's rotation on dynamics with a focus on the ocean circulation. We are aware of no study that has simulated the effect of changing the sense of
Earth's rotation using a full Earth system model (ESM) run long enough to reach a stationary state, and wherein most components in the Earth's oceans and biosphere (terrestrial land surface) were allowed to freely adapt to the changing conditions, and thereby define a new climate. Now, 200 years after Humboldt first introduced the idea of showing climatic data on a map, and a century after Köppen perfected this tradition, we ask how different would his and subsequent maps have looked had the Earth rotated in the opposite direction. In addition to shining a light on some of the aforementioned questions, these types of experiments provide important outof-sample tests of comprehensive climate models, the results of which, if reproduced by other groups, help shape the understanding of what aspects of Earth's simulated circulation systems are less sensitive to the details of how the simulation system is constructed.

\section{Model and experiments}

All simulations were performed with the ESM of the Max Planck Institute for Meteorology (MPI-ESM, version 1.2; Mauritsen et al., 2018), as developed for use in the Coupled Model Intercomparison Project 6 (CMIP6; Eyring et al., 2016). The model contains the atmospheric general circulation model ECHAM 6.3.02. This version contains some bug fixes and a different tuning but is not structurally very different from the version used in CMIP5 (Stevens et al., 2013). The land component JSBACH 3.10 (Reick et al., 2013) includes a dynamic vegetation model. Marine components are the general circulation Max Planck Institute ocean model (MPIOM 1.6.2p3; Jungclaus et al., 2013) and the marine biogeochemistry HAMburg Ocean Carbon Cycle (HAMOCC) model (Ilyina et al., 2013; Paulsen et al., 2017). The coarseresolution (CR) configuration of MPI-ESM is used. It consists of ECHAM6 run with a T31 spectral truncation and with 31 vertical hybrid (sigma-pressure coordinate) levels reaching up to $10 \mathrm{hPa}$. In physical space, the spectral transform grid on which parameterized processes are solved corresponds to 96 by 48 horizontal grid cells on a Gaussian grid. MPIOM has a curvilinear grid, with the poles located on Greenland and Antarctica. It has 120 by 101 grid cells in the horizontal and 40 levels in the vertical. A dynamicthermodynamic sea-ice model is included in MPIOM (Notz et al., 2013). The atmosphere and ocean are coupled once a day.

The forcing applied is the same as for the CMIP5 preindustrial control run (Giorgetta et al., 2013) and corresponds to 1850 climate conditions (fixed greenhouse gas conditions, insolation, aerosols, ozone). All simulations were started from an equilibrated climate state, resulting from a long 8000-year spin-up with some minor changes in the marine biogeochemistry module during the run. The control run (CNTRL) is simply a continuation of the spin-up and represents Earth's pre-industrial state. In the RETRO experi- 
ment, representing the retrograde rotating Earth, the sign of the Coriolis parameter was changed both in the atmospheric and oceanic model components. Additionally, the direction of the Sun's diurnal march was also reversed in the calculations of radiative transfer, thereby making sunrise consistent with the sense of the planetary rotations. Each simulation was integrated for 6990 model years. Whereas most physical variables were already reasonably well equilibrated after 2000 years (Fig. 1a), it took much longer for biogeochemical tracers to come close to equilibrium (Fig. 1b). Some slight drift in some water column inventories does however remain, due to the interactive sediment processes whose timescales are many millennia.

Despite the ambition to simulate the Earth system in a comprehensive manner, in a few aspects, the imprint of Earth's present-day climate was prescribed. Ice sheets, greenhouse gases, and aerosols were prescribed according to their present-day extent and pre-industrial concentrations, respectively. The aerosol prescription means that dust deposition data used to run the ocean biogeochemistry model reflect present-day estimates. Soil color and type were left unchanged in the land surface module JSBACH. The anthropogenic land use was prescribed according to 1850 conditions. These shortcomings in the model/experimental setup will be dealt with in future experiments.

The experimental setup was oriented on pre-industrial (piControl) conditions, as this run served as spin-up for $\mathrm{CN}$ TRL. Whereas the relative complete (with respect to the components) ESM was run long enough to reach equilibrium for the climate, some biogeochemical components revealed somewhat longer timescales as discussed above. Hence, for the analyses, the last 1000 years of each experiment were used. An exception is for the analysis of the atmospheric short-term variability, which requires 2-hourly model output and is based on the last 100 years of the experiments for which high temporal resolution output was retained.

\section{The atmosphere, its energy budget, and the surface climate}

At a first glance, changing the sense of planetary rotation incurs changes that Humboldt, or even Hadley (1735), might well have anticipated. The patterns of surface winds and the polarity of the temperature distribution, or the inclination of the isotherms, is reversed (Fig. 2). The changes in the winds are self evident, as the trades blow from the west in RETRO and the midlatitudes have surface easterlies. The change in the inclination of the isotherms is perhaps most evident in the distribution of the sea-ice extent; this is shown by the faint blue lines in Fig. 2a and b, as well as the sea-ice distributions themselves presented in Fig. 3. In RETRO, winter sea ice extends southward, enveloping Great Britain and reaching as far south as the Bay of Biscay in the northeast Atlantic, whereas the Canadian province of Newfoundland and
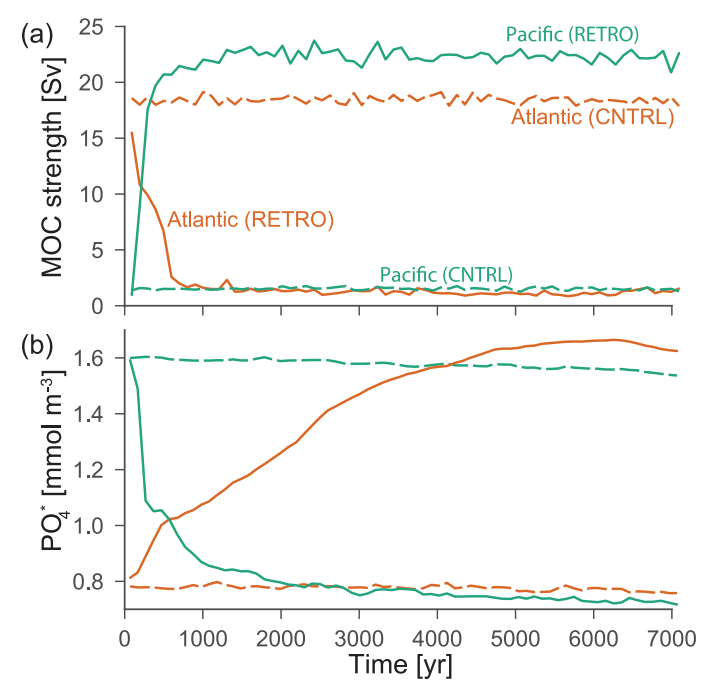

Figure 1. Time series (100-year means) of meridional overturning circulation for the Atlantic (orange) and Pacific (turquoise) at $30^{\circ} \mathrm{N}(\mathbf{a})$; a water mass tracer $\left(\mathrm{PO}_{4}^{*}\right)$ at two locations in the northern Atlantic (mean of $28-38^{\circ} \mathrm{N}, 60-70^{\circ} \mathrm{W}$ ) and northern Pacific (mean of $28-38^{\circ} \mathrm{N}, 150-160^{\circ} \mathrm{W}$ ) (b). RETRO is shown by the solid lines and CNTRL by the dashed lines in both panels. $\mathrm{PO}_{4}^{*}$ $\left(\mathrm{PO}_{4}+\mathrm{O}_{2} / 172-1.5\right)$ combines concentrations of phosphate and oxygen in such a way that, to first order, biological impacts are eliminated and thus can be used as a (quasi-)conservative property, which in the prograde world is used to track the contributions of North Atlantic deep water (NADW) and Antarctic bottom water $(\mathrm{AABW})$ to the ventilation of the deep Pacific and Indian Ocean (Rae and Broecker, 2018).

Labrador are free of sea ice in winter. Similar changes are evident in both the Aleutian Basin of the North Pacific and in the Pacific basin of the Southern Ocean. These changes are also evident in the tropical sea surface temperatures, with the region of warmest temperatures broadening to the east in RETRO as compared to a westward broadening in CNTRL (Fig. 2).

Over the continents, the shifting isotherms mean that the eastern continental margins warm and the western lands cool in RETRO as compared to CNTRL. In the midlatitudes, these changes are skewed (reflecting the changing inclination of Humboldt's isotherms) so that the cooling in the western lands is amplified poleward, and the warming is strengthened toward the Equator. Strong warming, for instance, is evident in the southeast of Brazil (Rio de Janeiro), over the southeastern states (Atlanta) of the US, and over southeastern China (Guangzhou and the Pearl River Delta region). The strongest cooling is over the ocean, in association with winter sea ice, particularly over the North and Baltic seas, although west Africa, which is very warm in CNTRL, also cools substantially, as does British Columbia in present-day Canada. The magnitude of these changes have the effect that - from a temperature perspective - the African-European landmasses cool, and the Americas warm (Fig. 2c). Over the ocean, the 

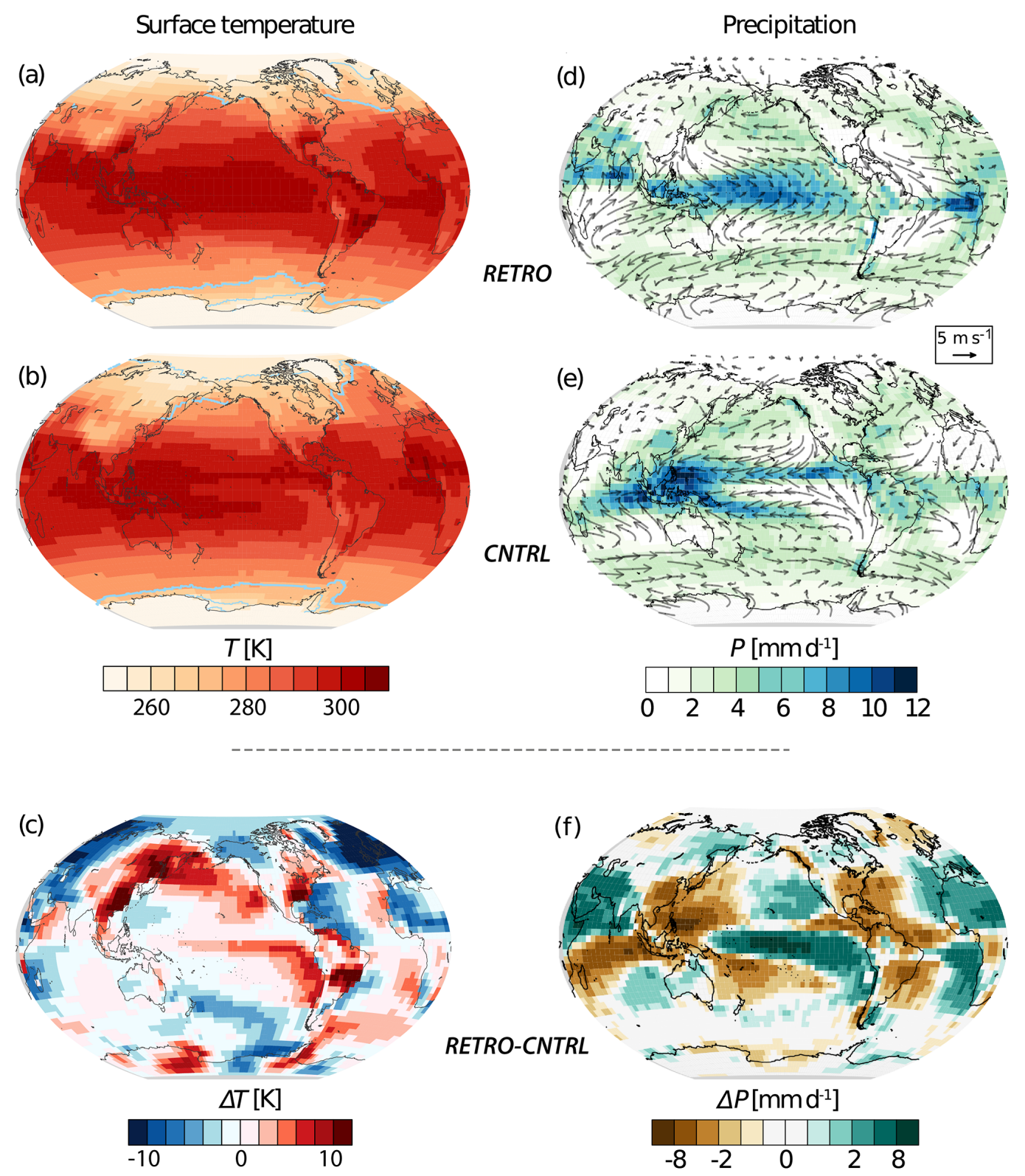

Figure 2. Annual averaged surface temperature in RETRO (a), CNTRL (b), and the difference between both simulations (c). The light blue lines indicate the locations of 1 and 11 months of sea-ice coverage; annual precipitation in RETRO (d), CNTRL (e), and the difference between the two simulations (f). The curly vectors depict the annually averaged $10 \mathrm{~m}$ wind. The seasonal cycle is shown in videos in https://doi.org/10.5446/36560, https://doi.org/10.5446/36556, https://doi.org/10.5446/36557, https://doi.org/10.5446/36559 and https://doi. org/10.5446/36555.

cold upwelling waters evident in the present-day east equatorial Pacific largely vanish, rather than shift, in RETRO. Figure 2 shows only a hint of a cold tongue stretching eastward from east Africa in the equatorial Indian Ocean.

To a large extent, the temperature changes also reflect changes in patterns of precipitation. Circulation changes, underlying changes in the inclination of the isotherms, are evident in changes in the isohyets (lines of constant precipi- tation; Fig. 2). The simulated warming of the southeastern regions of the continents coincides with marked drying, as precipitation is displaced to areas of present-day deserts in RETRO (Fig. 2d and e). As was the case for temperature, some extracontinental-scale changes are evident as again the roles of the Americas and the African-European land masses are exchanged. The latter becomes substantially wetter as a whole, particularly over Africa and the Mediterranean, and 

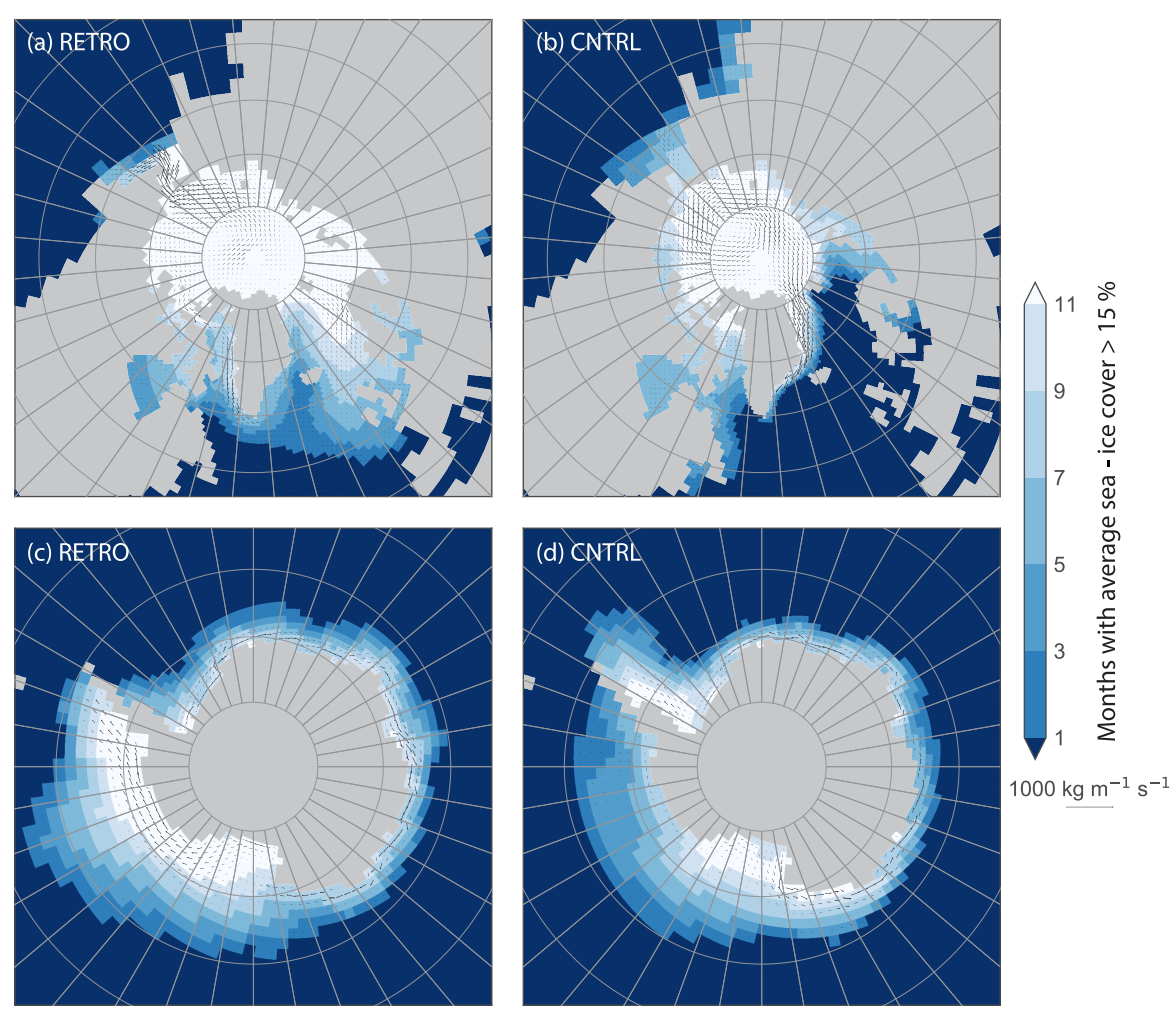

Figure 3. Duration of sea-ice cover in RETRO (a, c) and CNTRL (b, d). The vectors show annual mean sea-ice transport. For technical reasons, no sea-ice transport is displayed near the North Pole. The seasonal cycle of sea-ice coverage is shown in a video in https://doi.org/ $10.5446 / 36557$.

the former substantially drier (Fig. 2f). Precipitation in the tropics shifts from the western oceans, where it is stronger north of the Equator, particularly in the Pacific, to the eastern oceans and then south of the Equator, as in the Atlantic. This results in the zonally averaged precipitation becoming slightly stronger south of the Equator, a point that we rejoin below.

RETRO also exhibits substantial changes in its monsoons and deserts, something that might have been anticipated based on earlier work by, e.g., Rodwell and Hoskins (1996). Whereas in CNTRL tropical precipitation, and the velocity potential (at $200 \mathrm{hPa}$ ) to which it is related, is strongly focused around the western Pacific warm pool and AsianAustralian monsoon complex, in RETRO there is a greater dislocation between the land and ocean influenced precipitation. Over Asia, the monsoon is displaced westward in RETRO, centering over the Arabian Peninsula. Atmospheric convection over the oceans, meanwhile, follows the warm waters to the east in RETRO, and becomes more prevalent over the central and eastern Pacific and the southeastern Atlantic. The area with the largest amount of annual precipitation is located near Ascension Island in the southern tropical Atlantic $\left(8^{\circ} \mathrm{S}, 14^{\circ} \mathrm{W}\right)$, which takes on a climate more like present-day Palau $\left(8^{\circ} \mathrm{N}, 134^{\circ} \mathrm{E}\right)$. Overall, the dislocation between oceanic (warm-pool) and terrestrial (monsoon) precipitation in RETRO results in a more tripolar, rather than monopolar, tropical precipitation pattern, with distinct centers of precipitation over the Middle East, extending into north Africa, over the southeast Atlantic, and into the central Pacific. These changes are reflected in the $200 \mathrm{hPa}$ velocity potential (not shown), which becomes seasonally more varying and less monopolar in RETRO as compared to CNTRL.

To assess changing extratropical precipitation patterns, we have also tracked individual extratropical cyclones, defined as local minima of mean sea level pressure, in both RETRO and CNTRL. The track densities obtained during DJF in the Northern Hemisphere are presented in Fig. 4. Additional results for the tracking of cyclones during JJA in the Southern Hemisphere are shown in Fig. E2. As expected given the changed sense of the zonal winds, the storms track westward rather than eastward in the midlatitudes. This analysis (Fig. E1) shows that changes in their characteristics (such as number, lifetime, growth rate, or intensity) are small, although a tendency for slightly $(2 \mathrm{hPa})$ more intense storms in RETRO is evident. This may be related to strengthening meridional temperature gradients, as discussed near the end of this section. The tracks of storms, however, change more substantially as they move from regions of the westernboundary currents in CNTRL to become more land centered (RETRO) in the Northern Hemisphere, with particu- 

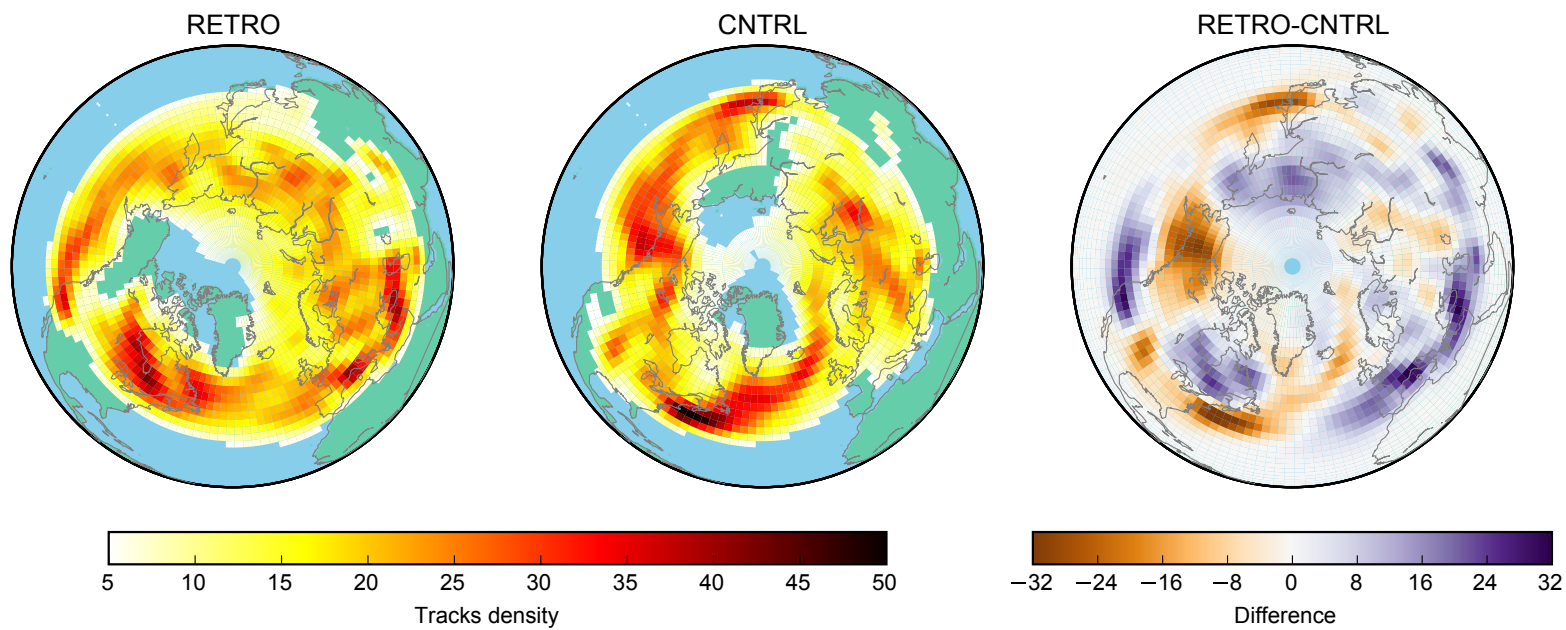

Figure 4. Track density (number of tracks per season for a unit area equivalent to a $5^{\circ}$ spherical cup) computed for the Northern Hemisphere during the December-January-February (DJF) season. The tracking is performed using 2-hourly mean sea level pressure (MSLP) data; storms are defined as local minimum of MSLP and are tracked during their lifetime using the methodology described in Hoskins and Hodges (2002). The data are seasonally averaged over the last 100 years of each simulation. In the first two plots on the left track, density for RETRO and CNTRL is shown; values below 5 are masked for the sake of visualization. Shown in the rightmost plot is the difference between RETRO and the CNTRL simulation without any masking applied. For the Southern Hemisphere version of this figure, see Fig. E2.

larly strong storm activity extending from the Caspian Sea and Arabian Sea through the northern Mediterranean (see videos in https://doi.org/10.5446/36561 and https://doi.org/ 10.5446/36555). This has large implications for the climate of north Africa and the Middle East but also acts to freshen the Atlantic at the expense of the Indo-Pacific oceans, with implications for the meridional overturning circulation (see Sect. 5). Further to the west, storms are most pronounced along the northern boundary of the Great Lakes (Fig. 4), east of the continental divide.

Changes in the storm tracks and trade winds lead to significant changes in the atmospheric energy transport, specifically in the moist static energy transport as shown in Fig. 5. Large amounts of moist static energy are transported from the Atlantic towards north Africa and the Middle East, where they have large implications for the regional climate. This transport persists through all seasons, except winter, when the trade winds are deflected southward across Nigeria towards equatorial Africa (not shown) extending into the Indian Ocean. Further, moisture is transported from the Indian Ocean across India, Pakistan, and the Middle East towards the Mediterranean Sea during all seasons except fall (Fig. 5). The enhanced moisture flux towards north Africa and the Middle East from the Atlantic and Indian Ocean provides a proximate explanation for the significant greening in these areas (Sect. 4). It also indicates a strong interplay between the trade winds over the Atlantic and the storm track over the Middle East.

Changing the direction of the diurnal path of the Sun has only minor influence on the climate but contributes to a southward shift of the ITCZ over the tropical Atlantic and a wetter climate over the Sahara. This is shown in Appendix B, and confirms that major circulation changes seen in RETRO versus CNTRL are ultimately dynamically driven through changes in the sign of Earth's absolute angular momentum.

Despite large regional shifts in circulation patterns, the globally averaged energy budget of RETRO hardly differs from that of CNTRL, and those differences that do emerge tend to be smaller than our ability to match the energy budget as derived from observations (Stevens and Schwartz, 2012; Stephens et al., 2012). Figure 6 is adapted from Stevens and Schwartz (2012) and shows that RETRO is slightly cooler (by about $0.14{ }^{\circ} \mathrm{C}$, with less upwelling terrestrial radiation from the surface; see Table 1), cloudier, and wetter. The increase in cloudiness is evident in a slight increase in planetary albedo, with an additional $1 \mathrm{~W} \mathrm{~m}^{-2}$ of reflected solar radiation. Surface turbulent moisture fluxes are larger and sensible heat fluxes are smaller in RETRO. These changes are consistent with more terrestrial radiation to the surface, indicative of an atmosphere that cools and hence rains more. The surface cooling in RETRO is manifested entirely in the Northern Hemisphere, as the Southern Hemisphere actually warms by $0.28^{\circ} \mathrm{C}$. In RETRO, the difference between the average temperature of the Northern Hemisphere and Southern Hemisphere is $-0.40{ }^{\circ} \mathrm{C}$, as compared to $+0.57^{\circ} \mathrm{C}$ in $\mathrm{CN}$ TRL. Concomitantly, almost all of the change in the downward longwave feedback $\left(5.7 \mathrm{~W} \mathrm{~m}^{-2}\right)$ is in the Northern Hemisphere, and almost all of this is over land.

Changes in the mean energy budget could be expected to affect the zonal distribution of precipitation. Building on the ideas developed by Kang et al. (2008, 2009) and Frierson et al. (2013), Bischoff and Schneider (2014) argue that an in- 

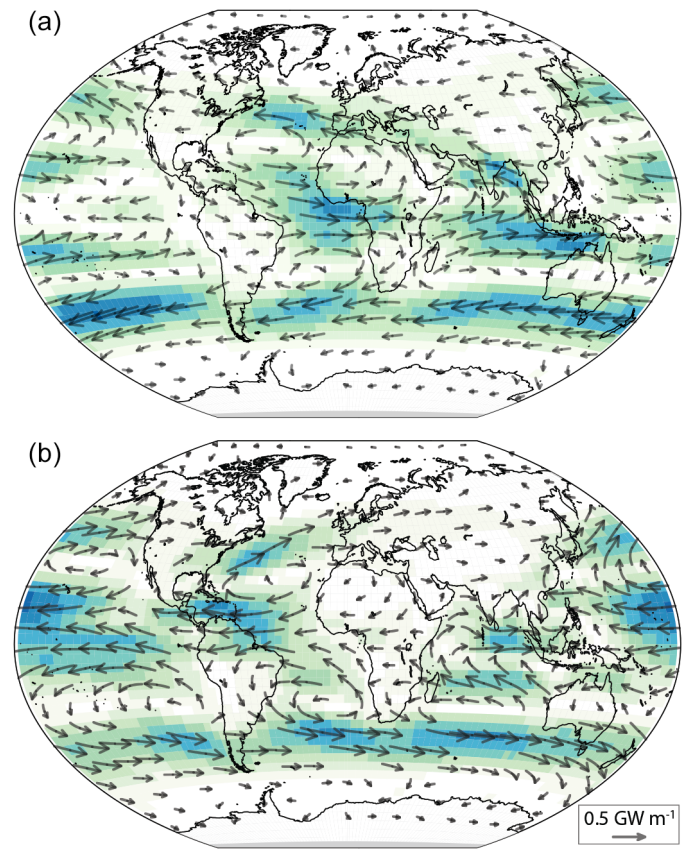

Moist static energy transport [GW m $\mathrm{m}^{-1}$ ]

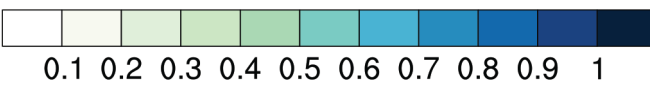

Figure 5. Moist static energy transport for RETRO (a) and CNTRL (b). To calculate the transport, we use 2-hourly data of velocities, surface pressure, temperature, and specific humidity (Keith, 1995). The data are averaged over the last 100 years of the simulation.

crease of energy release into the tropical atmosphere would shift the zero crossing of the vertically and zonally averaged moist static energy transport (the energy flux Equator) equatorward. Likewise, this way of thinking suggests that the strong increase in the RETRO Northern Hemisphere meridional temperature gradients implies a strengthening of the northern hemispheric energy fluxes which should also be accompanied by a southward shift of the ITCZ. Such a shift in the ITCZ is indeed pronounced in the simulations (Fig. 7a). The shift is also predicted by the change in the energy budget Equator (Fig. 7b, and inset), although not by the magnitude of the shift, nor does its position correlate well with the actual position of the precipitation maximum. These discrepancies might be related to changes in the zonally asymmetric circulation as earlier argued by Wallace et al. (1989) and Philander et al. (1996). To the extent the changes in precipitation are consequences of the changed hemispheric energy budget, they point to a possible role for ocean circulation and its disproportionate impact on the northern hemispheric ice sheets and temperature gradients, particularly over the North Atlantic. Reversing the sense of the planetary rotation does not, however, affect the distribution of land masses, so that differences between RETRO and CNTRL suggest that hemi-
Table 1. Changes in precipitation and surface temperature. For these entries, the tropics are defined as between $22.3^{\circ} \mathrm{S}$ and $22.3^{\circ} \mathrm{N}$.

\begin{tabular}{lcccc}
\hline \multicolumn{7}{c}{ Global } & NH & SH & Tropics \\
\hline \multicolumn{4}{l}{ Surface temperature (K) } \\
\hline RETRO & 287.42 & 287.21 & 287.64 & 298.98 \\
CNTRL & 287.56 & 287.76 & 287.36 & 298.53 \\
\hline \multicolumn{2}{l}{ Precipitation (mm day ${ }^{-1}$ ) } \\
\hline RETRO & 3.11 & 3.18 & 3.05 & 4.09 \\
CNTRL & 3.04 & 3.04 & 3.04 & 4.05 \\
\hline
\end{tabular}

spheric asymmetries in the distributions (as opposed to the shape) of continents (i.e., the fact that Antarctica is in the Southern Hemisphere) are at least not sufficient to explain why the ITCZ is mostly north of the Equator.

Many of the points discussed above are amplified by an inspection of the latitude-height description of the zonally averaged circulation. Figure 8a shows the differences between RETRO and CNTRL of annually and zonally averaged temperatures. Figure $8 \mathrm{~b}$ presents the corresponding annually and zonally averaged zonal winds. The surface temperature anomaly pattern shows the tropical warming in RETRO and the strong northern hemispheric cooling. The subtropical jets in RETRO are shifted northwards, i.e., equatorwards in the $\mathrm{SH}$ and polewards in the $\mathrm{NH}$, and slightly increased in magnitude. This is consistent (through the thermal wind balance) with changes in tropospheric temperatures whereby the highlatitude cooling in RETRO is much more pronounced in the Northern Hemisphere. This pattern of tropical warming and high-latitude cooling implies greater baroclinicity at midlatitudes but is accompanied by relatively little change in storm activity (see above), suggesting that enhanced northern hemispheric energy fluxes are mostly attributable to the changing enthalpy gradients.

As typical for climate model simulations of global warming, the tropical warming is stronger in the free troposphere than at the surface and reaches about $1.7 \mathrm{~K}$ around $300 \mathrm{hPa}$. Also typical for a globally warmer tropical troposphere is the increase of the cold-point tropical tropopause, i.e., the coldest point in the tropical tropopause region, as one might also expect if the tropopause temperature is radiatively controlled following the ideas of Zelinka and Hartmann (2010), which in RETRO is about $0.6 \mathrm{~K}$ warmer than in CNTRL.

A warmer cold-point tropopause and the resulting increased water vapor entry into the stratosphere is the likely cause of an about $13 \%$ larger specific humidity in the lower to middle stratosphere in RETRO (not shown). More stratospheric water vapor is a plausible reason for the, in general, lower stratospheric temperatures.

Changing the planetary rotation should, of course, to a first order cause a reversal of zonal winds. Figure $8 \mathrm{~b}$ shows 


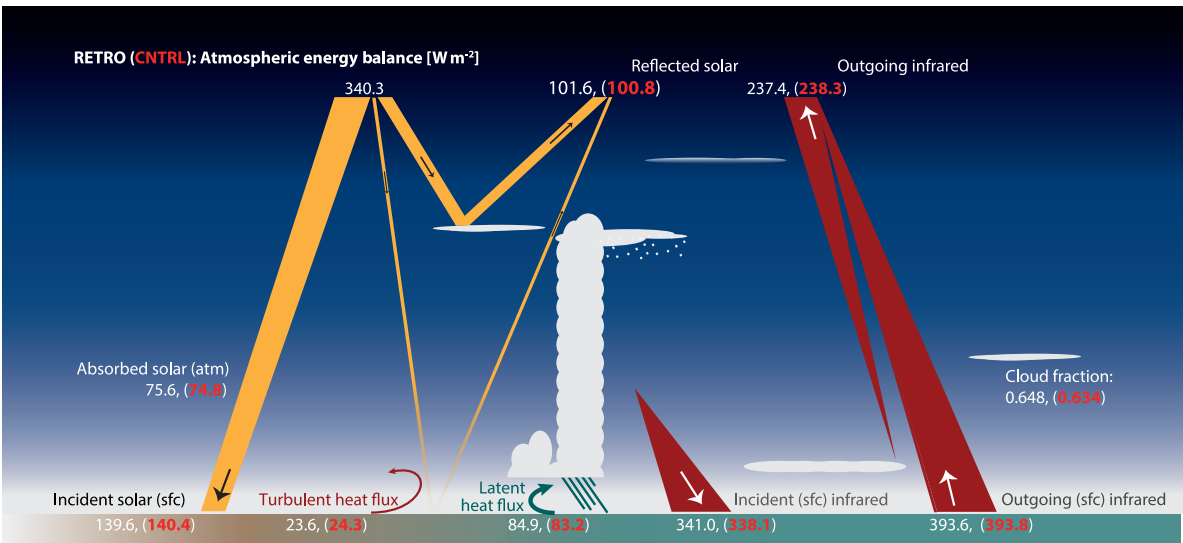

Figure 6. Globally averaged energy budget contributions for RETRO and CNTRL.

(a)

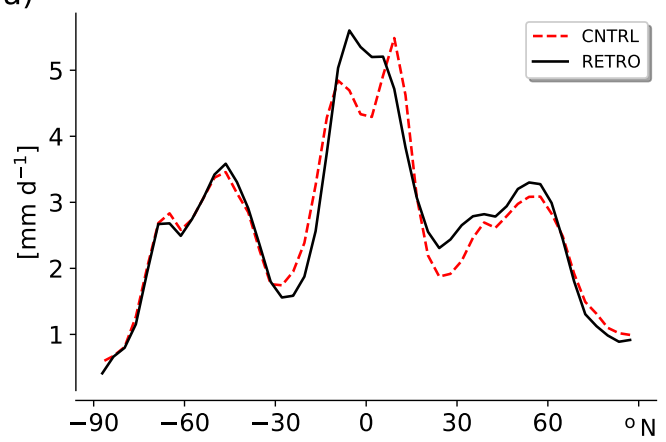

(b)

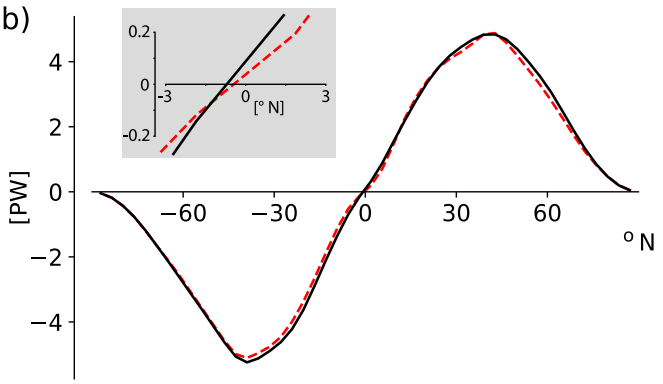

Figure 7. Zonally and annually averaged (a) precipitation, and (b) atmospheric energy flux for RETRO (black, solid) and CNTRL (red, dashed). The inset in panel (b) shows the atmospheric energy flux (computed as the integral of the vertical heat flux convergence as a function of latitude) in the vicinity of the zero crossing near the Equator.

the sum of annually and zonally averaged zonal winds of RETRO and CNTRL, which indicates second-order effects, i.e., deviations from a simple change in sign. Changes in the stratospheric circulation should be interpreted with caution due to the model top in the middle stratosphere at $10 \mathrm{hPa}$. However, the strongest stratospheric cooling, which occurs in the polar Northern Hemisphere, is dominated by a cooling in boreal winter, which further contributes to northern hemispheric baroclinicity, and is related to a stronger polar vortex in RETRO. The average eddy heat flux entering the stratosphere in boreal winter between 40 and $80^{\circ} \mathrm{N}$ is weaker in RETRO by about $15 \%$ (not shown), thereby helping to explain the temperature changes required to balance this stronger polar vortex. The changes in tropospheric flow patterns are thus connected to the stratosphere. The latitude dependence of the temperature signal in the southern stratosphere, although consistent with changes in vertical motion, is less straightforward to interpret.

In two sensitivity experiments (abrupt quadrupling of atmospheric $\mathrm{CO}_{2}, \mathrm{CNTRLx} 4$, and RETROx4), the climate sensitivity was investigated. Details are given in Appendix C. In general, RETROx4 showed a higher climate sensitivity (approximately $10 \%$ to $15 \%$ ). In spite of the large differences in tropical climate, the strength of the tropical cloud effect seems to be rather similar between the prograde and the retrograde simulations. A striking difference appears in the long-term equilibration (years 1000-2500), where CNTRLX 4 shows a change towards much faster equilibration at a lower level which is absent in RETROx4. This difference is connected to differences in the heat uptake of the deep ocean.

\section{Land surface and biosphere}

Köppen, in his book Die Klimate der Erde (1923), outlined his ideas regarding how continents impart zonal asymmetries in climate using his classification system applied to an idealized continent. For the purposes of the present discussion, Köppen's idealized continent has been redrafted and is presented in Fig. 9. The expectation inherent in this idealization is that a retrograde rotating Earth would experience mirror symmetry about the north-south axis in its climate zones.

As might have been expected given the discussion of the previous section, predictions based on Köppen's idealized continent, both for the distribution of climate zones in the present-day climate, and for the expected mirror symmetry for a retrograde rotating Earth are well supported by $\mathrm{CN}$ - 

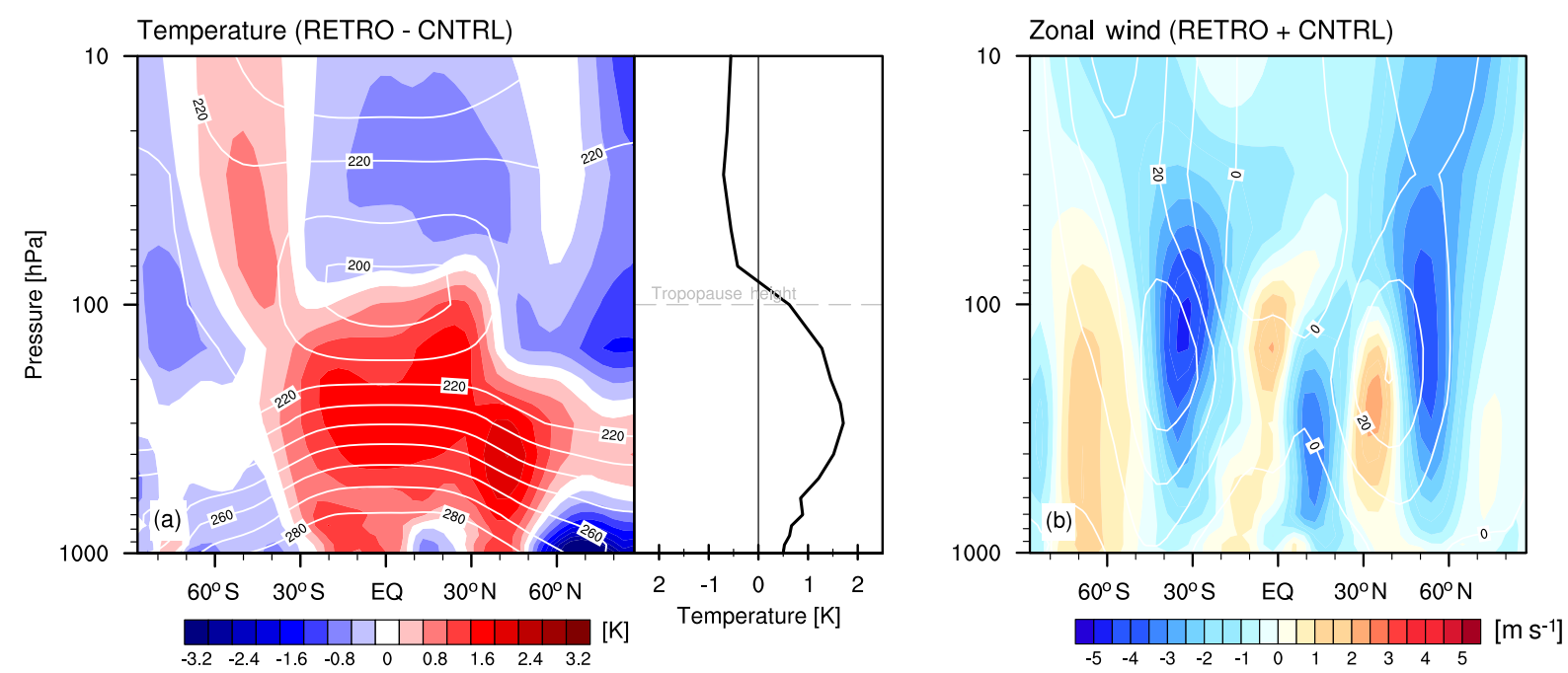

Figure 8. (a) Annually and zonally averaged temperature difference between RETRO and CNTRL (left) and its tropical (20 $\mathrm{S}$ to $20^{\circ} \mathrm{N}$ ) average (right). The tropopause level indicated in the right panel refers to the cold-point tropopause of the control case. (b) Annually and zonally averaged zonal wind sum of RETRO and CNTRL. White contour lines show the isotherms and isotachs of the control simulation with a contour interval of (a) $10 \mathrm{~K}$ and (b) $10 \mathrm{~m} \mathrm{~s}^{-1}$.

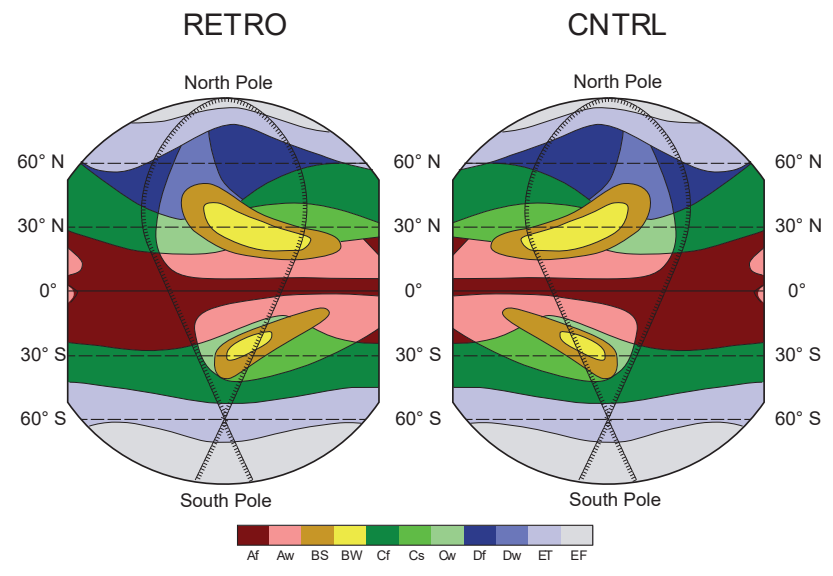

Figure 9. Classification of climate zones for an idealized continent, the Klimarübe, following Köppen (1923). First letters in the legend are main climate types: A: equatorial, B: arid, C: warm temperate, D: snow, and E: polar. Second letters are precipitation regimes: W: desert, S: steppe, f: fully humid, s: summer dry, w: winter dry, T: tundra, and F: ice cap.

TRL and RETRO. This is shown, using the same indication of major climate zones, in Fig. 10. CNTRL reproduces both the north-south asymmetry associated with more northern hemispheric land masses as reflected by the emergence of cold winter climates (Dw and Df) in the Northern Hemisphere, and the east-west asymmetry of a variety of features. For instance, the shift from subtropical deserts (BW) in the continental southwest toward moist temperate climates in the continental southwest at subtropical latitudes is well evident in the contrast between west Africa and southeast Asia. To a
Table 2. Global area of main vegetation groups averaged over the last 1000 years of the experiment.

\begin{tabular}{lrrr}
\hline Area covered (million $\mathrm{km}^{2}$ ) & RETRO & CNTRL & Difference \\
\hline Permanent deserts & & & \\
\hline Global & 31.2 & 41.8 & -10.6 \\
NH & 21.0 & 34.1 & -13.1 \\
SH & 10.2 & 7.7 & +2.5 \\
\hline Woody vegetation & & & \\
\hline Global & 46.3 & 41.3 & +5.0 \\
NH & 33.4 & 25.0 & +8.4 \\
SH & 12.9 & 16.3 & -3.4 \\
\hline Herbaceous vegetation & & & \\
\hline Global & 50.0 & 44.4 & +5.6 \\
NH & 41.1 & 36.4 & +4.7 \\
SH & 9.0 & 8.0 & +1.0 \\
\hline
\end{tabular}

first approximation in a retrograde rotating Earth, these features do appear with mirror symmetry (Fig. 10b).

There are however some differences that would not have been predicted from just mirroring the idealized continent. Most prominent is the shift in deserts from the EurasianAfrican continental mass to the Americas, with a greater center of mass over the subtropical southern hemispheric continents. This change is consistent with the inferences of the last section, whereby in RETRO many of the climate features associated with present-day Europe/Africa and North/South America are exchanged. 

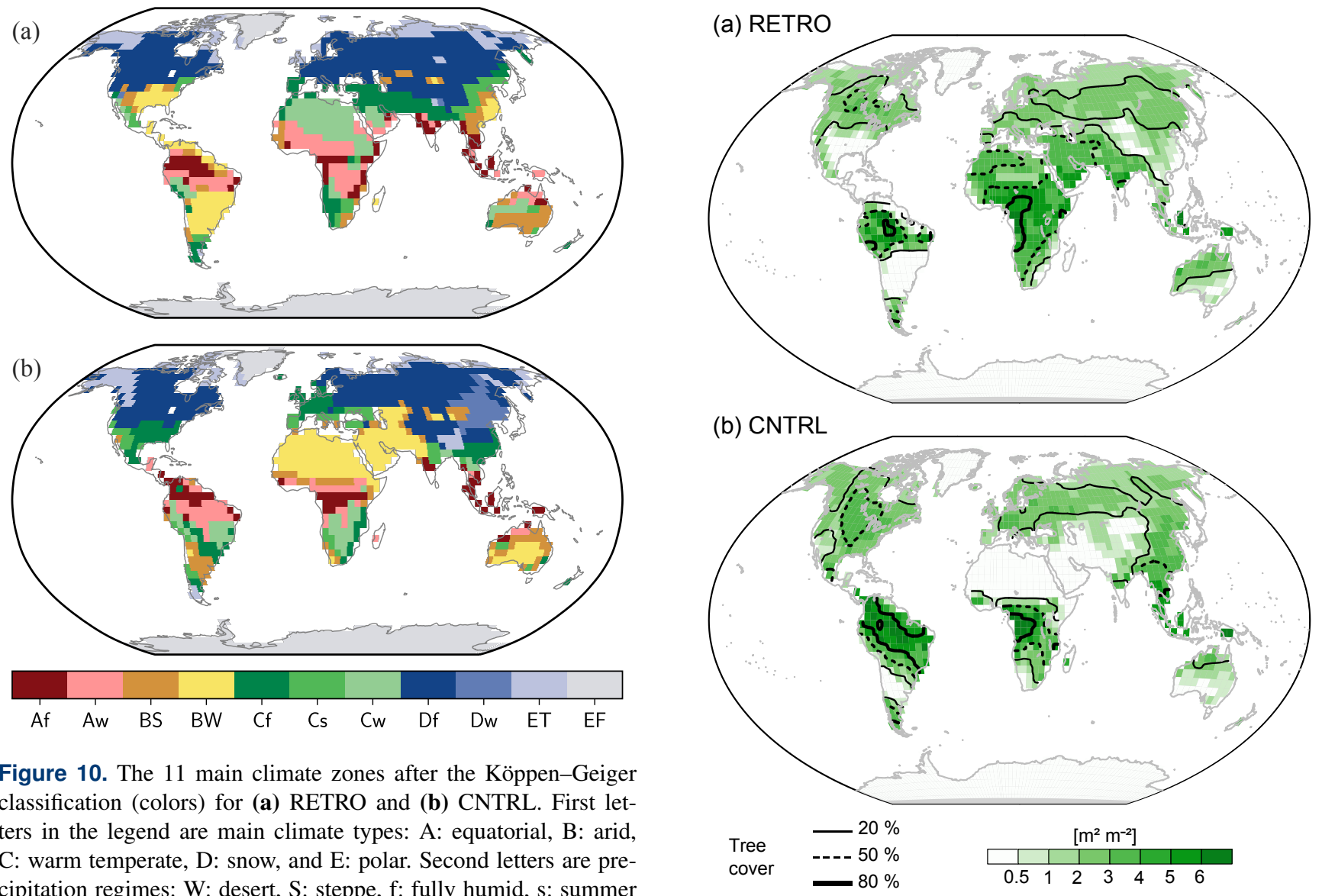

Figure 10. The 11 main climate zones after the Köppen-Geiger classification (colors) for (a) RETRO and (b) CNTRL. First letters in the legend are main climate types: A: equatorial, B: arid, C: warm temperate, D: snow, and E: polar. Second letters are precipitation regimes: $\mathrm{W}$ : desert, $\mathrm{S}$ : steppe, f: fully humid, s: summer dry, w: winter dry, T: tundra, and F: ice cap.

The complete replacement of the wide desert belt from west Africa to the Middle East by forests and humid grasslands is more quantitatively measured by changes to the leaf area index (LAI; Fig. 11). Changes in LAI also illustrate the degree to which the retreat of desert climates in Africa and Eurasia is accompanied by an extensive formation of dry climates in South and North America. Southern Brazil and Argentina become the Earth's biggest deserts and the southern states of the United States see a dramatic climate shift from a fully humid climate towards a complete aridification. In general, many dry regions are simulated in RETRO, but extreme deserts - like the present-day Sahara - are less widespread. Changes are, as discussed in Sect. 3, consistent with circulation and precipitation changes over these same regions.

The global area covered by permanent deserts is reduced by about $25 \%$ from $42 \times 10^{6}$ and $31 \times 10^{6} \mathrm{~km}^{2}$ (see Table 2). Woody and herbaceous vegetation fills the new vegetated areas in about equal measure. The greening is concentrated over northern hemispheric land masses (desert areas shrink by nearly $40 \%$ ) and mostly attributed to the aforementioned vanishing of the wide desert belt from west Africa to the Arabian Peninsula. Over southern hemispheric land masses, deserts and grasslands spread slightly, whereas the

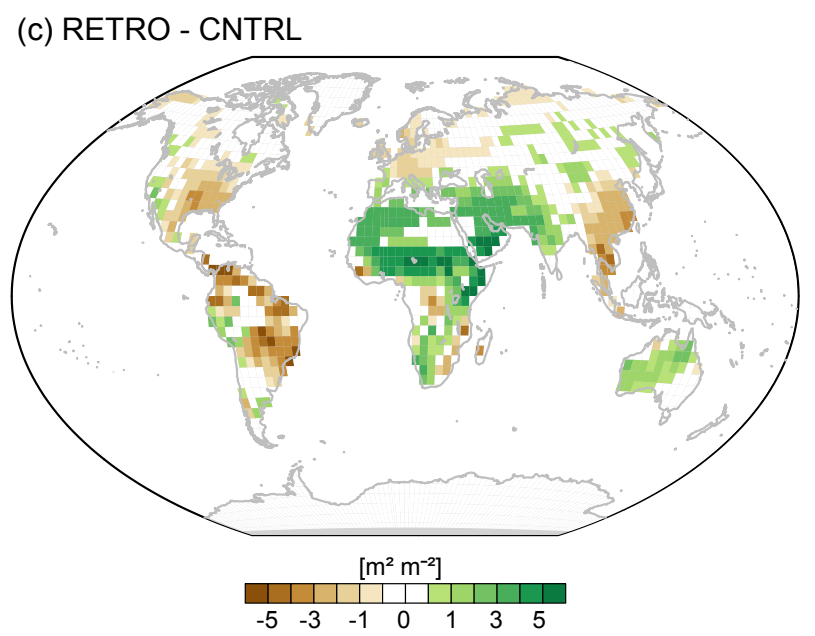

Figure 11. LAI (shaded) and tree cover (contours) for (a) RETRO and (b) CNTRL. Panel (c) shows the differences in LAI (see also video in https://doi.org/10.5446/36553).

tree-covered area is reduced by about $20 \%$. Tropical vegetation remains largely unaffected in Africa and Asia. In South America, the Amazon rain forest shrinks substantially, though. 
The greener climate in RETRO affects the global carbon storage on land, which increases by $86 \mathrm{PgC}$ compared to the CNTRL simulation. The globally integrated storage increase is composed of an increase by $215 \mathrm{Pg} \mathrm{C}$ in the Northern Hemisphere and a decrease of $130 \mathrm{PgC}$ in the Southern Hemisphere.

Based on previous experience (e.g. Claussen, 2009; Bathiany et al., 2010), we suppose that interactions between the biosphere and the atmosphere amplify or dampen the nearsurface climate changes. The reduced tree cover in the much colder and snowier Europe, for example, coupled with the greening of north Africa and the Middle East likely induces a large-scale and large-amplitude change to the surface albedo (Fig. 12). These changes are expected to modify the local climate directly, for instance, through enhanced near-surface cooling via the effect of reduced snow masking, or indirectly by inducing circulation changes. The depicted changes in surface albedo (Fig. 12) also hint at a limitation of our study. We have prescribed present soil albedo and land use as of $1850 \mathrm{CE}$. Hence, we expect that changes of soil albedo caused by an increase in soil carbon due to plants growing in the retrograde green Sahara (see Vamborg et al., 2011) could further decrease the surface albedo in that region or, vice versa, enhance the surface albedo in the retrograde deserts of the Americas. Likewise, the atmospheric aerosol remained unchanged in the simulations, with an interactive aerosol, precipitation changes over RETRO in Africa, and hence Sahara dust emissions would likely decrease; whether this would be compensated by substantial increases in emissions from other sources remains an open question.

Another prescribed present-day feature is the ice sheets. In the RETRO and CNTRL simulations, no permanent snow cover was simulated outside of the prescribed glaciated areas (not shown). Additionally, the simulated summer temperatures over the ice sheets (not shown) do not indicate a strong inconsistency between the prescribed ice sheets and the simulated climate both for RETRO and CNTRL. Therefore, we did not find a major inconsistency between the prescribed present-day ice sheet configuration and the simulated climate.

\section{Ocean physics}

As expected, the change of the sign of the Coriolis parameter has a marked impact on the ocean circulation (Fig. 14; see video in https://doi.org/10.5446/36551). Directly associated with this shift is a change in the sign of the zonal ocean velocity components. Subpolar and subtropical gyres shift their longitudinal positions and what used to be a western boundary current in CNTRL becomes an eastern boundary current in RETRO. These shifts cause significant changes in the SST patterns in the subtropical gyres. The strong poleward transport of warm water in the eastern boundary currents leads to a local warming and the missing poleward flow of warm wa-
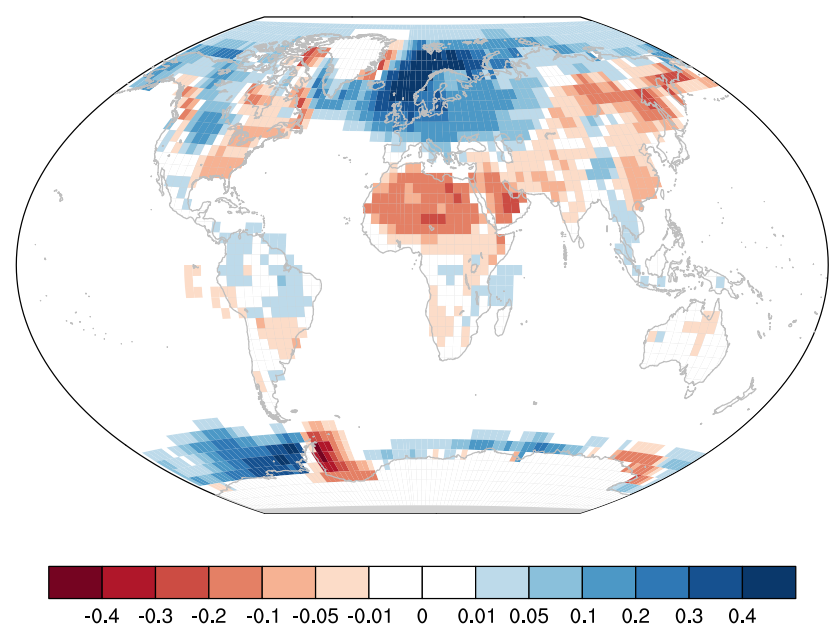

Figure 12. Differences in surface albedo (RETRO-CNTRL).

ters on the western side of the basins leads to a local cooling (Fig. 2a and c).

The Antarctic circumpolar current (ACC) reverses its direction and moves from east to west in RETRO. The Indonesian throughflow changes it sign and transports $21 \mathrm{~Sv}$ from the Indian Ocean to the Pacific. Besides, many of the gyres show substantial changes in strength. In RETRO, both subtropical and subpolar gyres in the North Atlantic become weaker than in CNTRL. The main cause for this is the lack of the thermohaline-driven overturning component in the Atlantic (see below), reducing the North Atlantic gyres to their wind-driven part. Further, the straight western coastline of the Americas enables the development of closed gyres in the Pacific in RETRO. In contrast, the gyres in CNTRL are affected by the openings along the highly structured AsianAustralian coastline. Especially the South Pacific subtropical gyre in RETRO becomes (with more than $130 \mathrm{~Sv}$ ) approximately 2.5 times stronger than in CNTRL.

In CNTRL, Antarctic bottom water is formed in the center of the Weddell Gyre. In RETRO, deep water formation in the Southern Hemisphere (as indicated by the maximum mixed layer depth; Fig. 14) takes place in the Atlantic sector of the Southern Ocean, close to the coast of Antarctica. In the Northern Hemisphere, the changes are more dramatic. In CNTRL, the model simulates an Atlantic meridional overturning circulation (MOC) of $19 \mathrm{~Sv}$. North Atlantic deep water is formed in the Nordic Seas and intermittently in the Labrador Sea. In RETRO, only intermittent convection down to $2000 \mathrm{~m}$ depth occurs in the North Atlantic (Fig. 14). The appearance of deep convection has a multidecadal timescale with a peak around 80 years. In the long-term mean, no clear North Atlantic deep water cell emerges in RETRO. Instead, the northeast Pacific exhibits strong formation of deep water (down to $3000 \mathrm{~m}$ ). This leads to a strong Pacific MOC of 23 Sv (Fig. 13). The core of the North Pacific deep water is slightly warmer and shallower than its North Atlantic equiv- 
alent in CNTRL. This indicates that the Atlantic and Pacific change their roles in CNTRL and RETRO.

Whereas the global poleward oceanic heat transport in the Northern Hemisphere is almost unchanged (1.56 PW in CNTRL versus $1.52 \mathrm{PW}$ in RETRO at $30^{\circ} \mathrm{N}$; Fig. $15 \mathrm{a}$ ), the distribution between the basins changes strongly. In CNTRL, more than half of the heat is transported in the Atlantic. In RETRO, the Pacific transports almost $80 \%$ of the heat. The transport in the Pacific is larger, as the gyre transport in the Pacific is stronger than in the Atlantic, which can be explained by the larger spatial extent of the basin. Thus, also in terms of the ocean heat transport, the Atlantic and Pacific have changed their roles. Due to the strong upwelling of colder subsurface water, the tropical Indian Ocean (north of $30^{\circ} \mathrm{S}$ ) becomes a strong heat sink for the atmosphere in RETRO (0.84 PW). This is in contrast to CNTRL, where the tropical Indian Ocean has a rather small net heat uptake (0.1 PW). In RETRO, the tropical Indian Ocean has de facto taken the role of the tropical east Pacific in CNTRL. This is also true for tropical SST variability. The leading mode in RETRO has its center of action in the Indian Ocean, in contrast to the El Niño mode in CNTRL. More details can be found in Appendix A. For the export of heat to the tropical Pacific, the reversed Indonesian throughflow plays a key role. In RETRO, the equivalent of the cold Humboldt Current flows northward in the western Indian Ocean along the coast of Mozambique.

The changes in ocean heat transport are also reflected in SST and sea-ice changes. In general, the North Atlantic is colder in RETRO, while the North Pacific is warmer (Fig. 2). The effect of the reduced ocean heat transport in the North Atlantic is amplified by the reduced wintertime mixed layer depth, which reduces the effective heat capacity of the surface ocean and thus leads to colder winter temperatures and extended sea-ice cover (Fig. 3).

In RETRO, the Atlantic north of $30^{\circ} \mathrm{N}$ is a strong sink for atmospheric moisture $(0.70 \mathrm{~Sv})$, and the net flux into the North Pacific is much smaller $(0.10 \mathrm{~Sv})$, whereas in CNTRL these values are almost equal (Fig. 15b). The net moisture loss of the Pacific north of $30^{\circ} \mathrm{S}$ is $0.30 \mathrm{~Sv}$; in the Atlantic, it is only $0.07 \mathrm{~Sv}$. In CNTRL, the role of the two oceans is reversed. In RETRO, the Atlantic gains moisture from the Indian Ocean by atmospheric moisture transport across the Middle East, which is strongest in spring and summer and loses moisture by the eastward transport across equatorial Africa. The transport across Central America is very small but directed towards the Atlantic, whereas in CNTRL a strong transport is directed towards the Pacific (Fig. 5). Consequently, the North Pacific surface salinity in RETRO is higher than in CNTRL; in the North Atlantic, surface salinity is reduced (see video in https://doi.org/10.5446/36558). This explains the shift of the deep water formation from the North Atlantic to the North Pacific described above.

Due to strong precipitation in RETRO, the Mediterranean and Red Sea no longer are marginal seas with net evapora-
Table 3. Global mean net primary production rate, biogenic material export flux at $100 \mathrm{~m}$, volume of oxygen minimum zones (OMZs), global mean denitrification, and ratio of denitrification to organic matter export flux on a percentage basis $\left(R_{\mathrm{den}}\right)$.

\begin{tabular}{lccc}
\hline & \multicolumn{3}{c}{ Net primary production $\left(\mathrm{Gt} \mathrm{C} \mathrm{yr}^{-1}\right)$} \\
\cline { 2 - 4 } & Bulk phytoplankton & Cyanobacteria & Total \\
\hline CNTRL & 49.97 & 3.09 & 53.05 \\
RETRO & 48.02 & 3.73 & 51.75 \\
\hline & \multicolumn{3}{c}{ Export flux } \\
\cline { 2 - 4 } & Organic matter & Opal shells & Calcite shells \\
& $\left(\mathrm{Gt} \mathrm{C} \mathrm{yr}^{-1}\right)$ & $\left(\mathrm{kmol} \mathrm{Si} \mathrm{s}^{-1}\right)$ & $\left(\mathrm{Gt} \mathrm{C} \mathrm{yr}^{-1}\right)$ \\
\hline CNTRL & 7.58 & 3464.0 & 0.54 \\
RETRO & 7.78 & 3422.7 & 0.49 \\
\hline & Volume of OMZ & Denitrification & $R_{\text {den }}$ \\
& $\left(10^{16} \mathrm{~m}^{3}\right)$ & $\left(\mathrm{Tg} \mathrm{N} \mathrm{yr}^{-1}\right)$ & $(\%)$ \\
\hline CNTRL & 3.90 & 109 & 1.07 \\
RETRO & 3.83 & 154 & 1.46 \\
\hline
\end{tabular}

tion (as in CNTRL). This has dramatic consequences for the overturning circulation in these basins. Whereas both basins today (and in CNTRL) are characterized by deep convection and a deep outflow of salty water, the circulation in RETRO is completely reversed. Both basins are well stratified and the main source of deep water is the inflow. The outflow at the surface is rather fresh, typical for estuarine circulations.

The lack of deep water formation in the North Atlantic and the Arctic and the changes in density lead to an increase in sea level in the Atlantic and the Arctic by typically $0.5 \mathrm{~m}$, whereas the sea level in the Pacific and the Indian Ocean decreases (not shown). This reverses the sea level gradient across Bering Strait and leads to a southward flow of fresh Arctic surface waters into the North Pacific.

The direction of the simulated changes is similar to the outcome of experiments by Smith et al. (2008) and Kamphuis et al. (2011), but in general the circulation changes found in our model are more similar to the results of Smith et al. (2008) than to the results of Kamphuis et al. (2011). Both studies showed a weakening of the Atlantic MOC together with a surface freshening in the North Atlantic and saltier surface conditions in the North Pacific. Whereas Smith et al. (2008) also showed a strong MOC in the Pacific, Kamphuis et al. (2011) obtain a state with a relative weak MOC both in the Atlantic and Pacific.

\section{Ocean biogeochemistry}

Ocean circulation is the key driver of spatial patterns of marine biogeochemical tracers. This implies large-scale patterns of these tracers follow the reversal of the ocean circulation (described in Sect. 5) and biogeochemical water mass trackers, such as $\mathrm{PO}_{4}^{*}$, mirror the transient behavior of the 


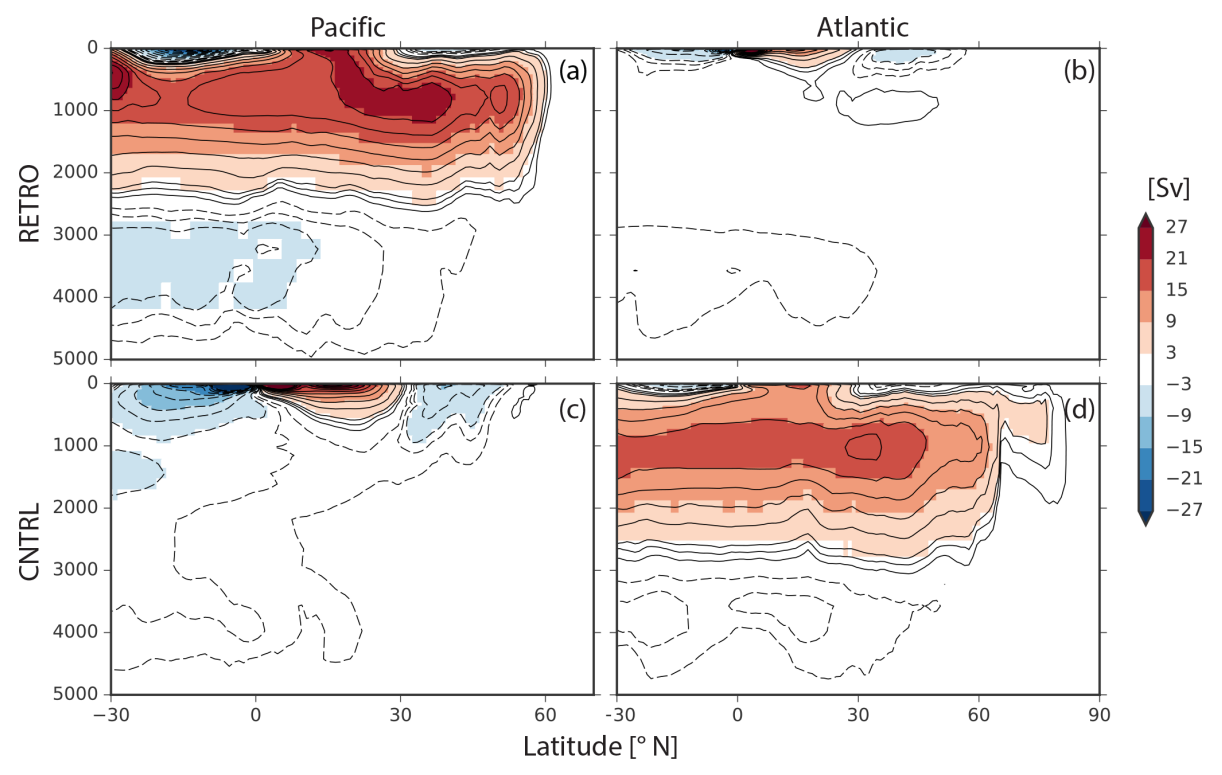

Figure 13. MOC stream functions. Outlines are at $\pm 1,2$, and multiples of $3 \mathrm{~Sv}$. The Indian Ocean MOC stream functions are shown in Fig. 17.
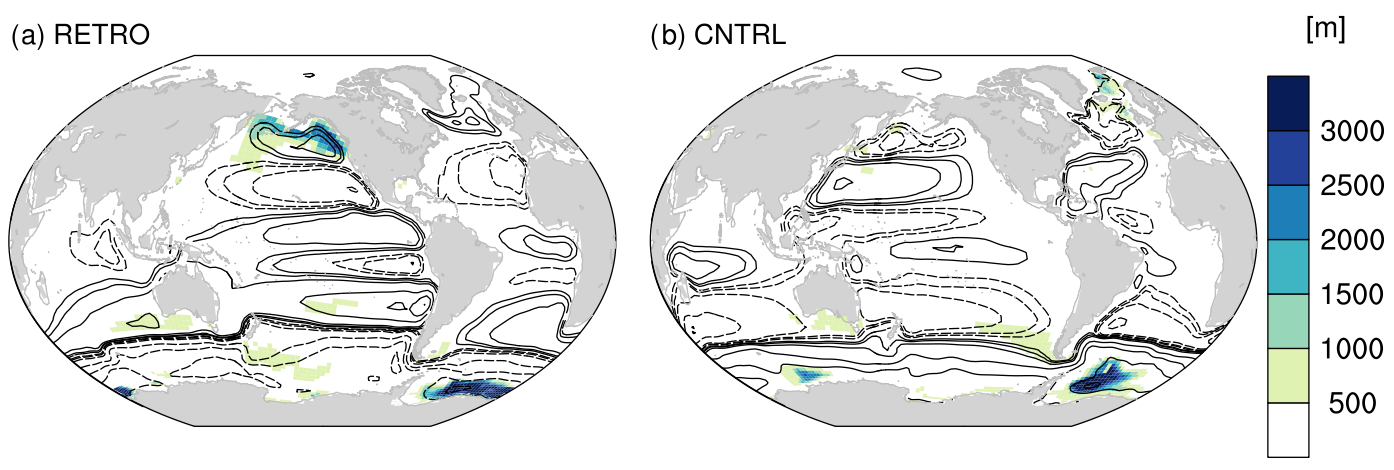

Figure 14. Maximum mixed layer depths and annual mean barotropic stream functions. Outlines are at $\pm 5,10,20,60,100 \mathrm{~Sv}$, and so on. (a) RETRO, (b) CNTRL.

MOC reversal though with longer equilibration timescales (Fig. 1b). Planetary-scale features such as zonal and global means are largely unaffected by the direction of Earth's rotation (Table 3). The changes in the Coriolis effect and wind patterns lead to a shift of eastern boundary upwelling systems to the western sides of ocean basins in RETRO (Fig. 16). In these upwelling systems, in general, primary production, and thus carbon storage in particulate organic matter (POM), is driven by a continuous supply of nutrients from greater depth into the sunlit surface layers (euphotic zone). Gravitational settling and subsequent remineralization of POM, a process being referred to as biological pump, lead to pronounced vertical gradients in all biogeochemical tracers. Exported organic material is remineralized under the consumption of oxygen. For this reason, hypo- or suboxic conditions are often found at intermediate depths in regions with high biological production such as upwelling systems. The global volume of these oxygen minimum zones (OMZs) is nearly identical in RETRO and CNTRL (Table 3; see also video in https://doi.org/10.5446/36552). Despite that, in CNTRL, three major OMZs are found on the eastern side of each ocean basin, while in RETRO there is one sizable OMZ in the Indian Ocean. Strong upwelling, which is also reflected in strong heat uptake, fuels biological production rates at levels not found in CNTRL. In combination with the circulation and the basin geometry of the Indian Ocean, this leads to very low ventilation and nutrient accumulation in the northern part of the basin (Fig. 17) and results in the development of this extended OMZ. One prominent characteristic of OMZs is that in the low oxygen environment denitrifying bacteria are able to access food energy by degradation of organic matter using nitrate $\left(\mathrm{NO}_{3}\right)$. Denitrification is limited to very low oxygen conditions (in the model $\mathrm{O}_{2} \leq 0.5 \mathrm{mmol} \mathrm{m}^{-3}$ ) and is the only remineralization process that selectively removes bioavail- 

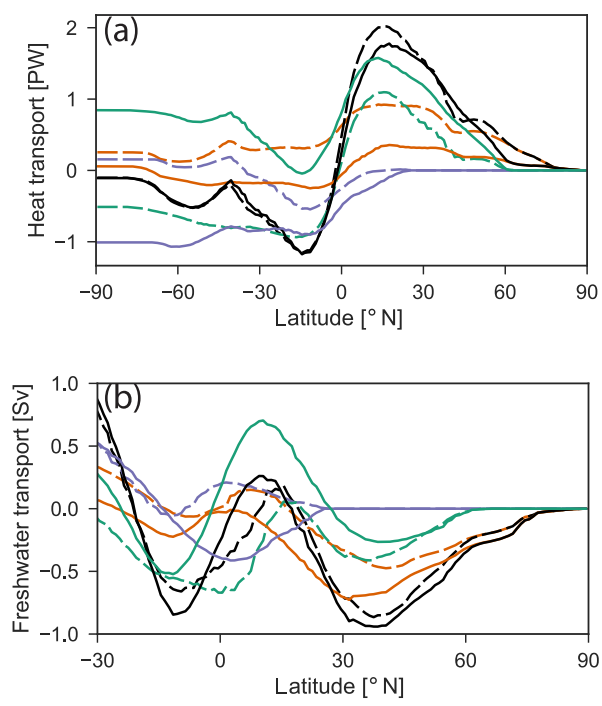

Figure 15. Northward implied ocean transport of (a) heat and (b) freshwater. Black: global, orange: Atlantic, turquoise: Pacific, and violet: Indian Ocean. Solid: RETRO, dashed: CNTRL.

able nitrogen. All other degradation processes, i.e., aerobic remineralization and sulfate reduction, convert organic material into phosphate, iron, and nitrate. In RETRO, global denitrification is about $50 \%$ higher than in CNTRL and takes place predominately in the northern Indian Ocean (Table 3; see also video in https://doi.org/10.5446/36554). As a consequence, upwelling of nitrate-depleted and phosphate-rich water $\left(\mathrm{N}^{*}=\mathrm{NO}_{3}-16 \cdot \mathrm{PO}_{4}<0\right.$; Fig. 18) results in a shift of the phytoplankton species composition (Fig. 17) with a dominance of cyanobacteria in RETRO. Most phytoplankton species need both nitrate and phosphate for their growth. Only cyanobacteria are able to grow on dinitrogen $\left(\mathrm{N}_{2}\right)$, as long as sufficient phosphate and iron are available (e.g., Sohm et al., 2011). In the prograde world, only few regions exist where the surface water is nitrate-depleted and phosphate-rich. Thus, cyanobacteria are outcompeted nearly everywhere by other phytoplankton species (bulk phytoplankton). In contrast, in RETRO, they become the dominant primary producer in the northern Indian Ocean. The change of the Earth's rotation direction and the subsequent development of an extended oxygen minimum zone in RETRO provoke plankton species compositions over large areas which have not been observed in the prograde world.

It was hypothesized that a warming climate and the consequential deoxygenation of the ocean (e.g., Breitbarth et al., 2007; Hutchins and Fu, 2017) trigger such an ecosystem shift with nitrogen-fixing cyanobacteria as a potential winner. Thus, the response nicely supports the possibility of these extreme changes in the ecosystem. It also demonstrates the model's ability to adapt to an unconventional forcing and to simulate phenomena which are a result of complex interaction of abiotic and biotic processes.
The model setup, of course, includes simplifications that might affect characteristics of the response. For example, due to lack of a dynamical aerosol model, we use dust deposition maps derived from a prograde model as a source of dissolved iron. Thereby, large ocean inputs occur downstream major deserts, such as from the Sahara into the Atlantic. A displacement of deserts as simulated by the land model in RETRO (see Sect. 4) would also imply a shift of dust deposition maximums. This might affect the relative importance of $\mathrm{P}$ and iron limitation of cyanobacteria (as described in Sohm et al., 2011). Hence, the availability of dissolved iron in RETRO is controlled by ocean circulation patterns and upstream consumption by plankton in regions where local aeolian supply is low due to the fixed (prograde) dust deposition field. On the contrary, some regions like the northern Indian Ocean receive potentially a higher iron supply by this dust field. However, the dominance of cyanobacteria in the northern Indian Ocean in RETRO is primarily a result of the interplay between the high equatorial primary production creating water masses depleted in nitrate and enriched in phosphate and iron and the ocean circulation with a northward transport and subsequent upwelling of these water masses (Fig. D1). Independent of aeolian iron supply, the lack of nitrate (Fig. 18) inhibits growth of bulk phytoplankton fostering the local dominance of cyanobacteria in the northern Indian Ocean.

Furthermore, atmospheric mixing ratios of $\mathrm{CO}_{2}$ are set to a constant global value. A simulation with a fully coupled carbon cycle would have allowed for assessing local interactions between land cover and subsequent $\mathrm{CO}_{2}$ emission changes driven, e.g., by the shifts in the Indian monsoon. However, we expect that main features of ocean carbon cycling would remain unaffected.

\section{Conclusion}

By performing experiments, where the sense of rotation of the Earth was changed, we aimed at better understanding climate with respect to hemispheric asymmetries and longitudinal distributions. Two simulations, each encompassing 6990 years forced by conditions thought to be representative of Earth's climate before the era of industrial combustion (i.e., 1850), are performed: one with a retrograde rotating Earth (RETRO) and the other being the control climate (CNTRL) of the prograde rotating Earth. The simulations, while endeavoring to be as comprehensive as possible, are not without limitations. For instance, their resolution is coarse, so as to expedite the long equilibration of the ocean and biogeochemical cycles, and some other constituents (ice sheets, soil properties, greenhouse gases, aeolian dust input, and the atmospheric aerosol) are held constant consistent with the present-day (or pre-industrial) prograde rotating Earth. These simplifications could be relaxed in future studies. Even so, the simulations are the first of their kind as two previous studies looked in a much more limited way, and over shorter 
(a) RETRO

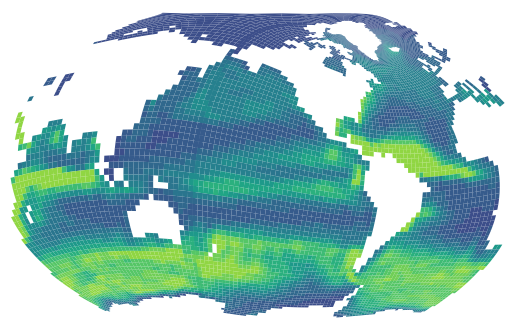

(b) CNTRL

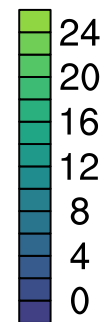

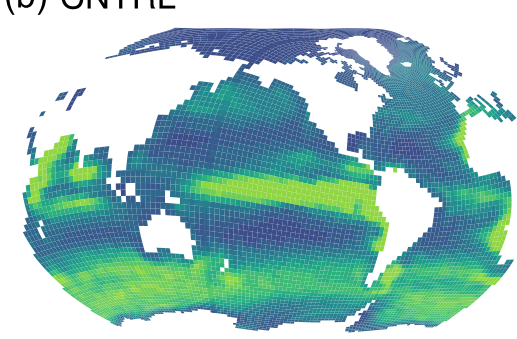

Figure 16. Net primary production ( $\mathrm{mol} \mathrm{C} \mathrm{m}^{-2} \mathrm{yr}^{-1}$ ). (a) RETRO and (b) CNTRL.
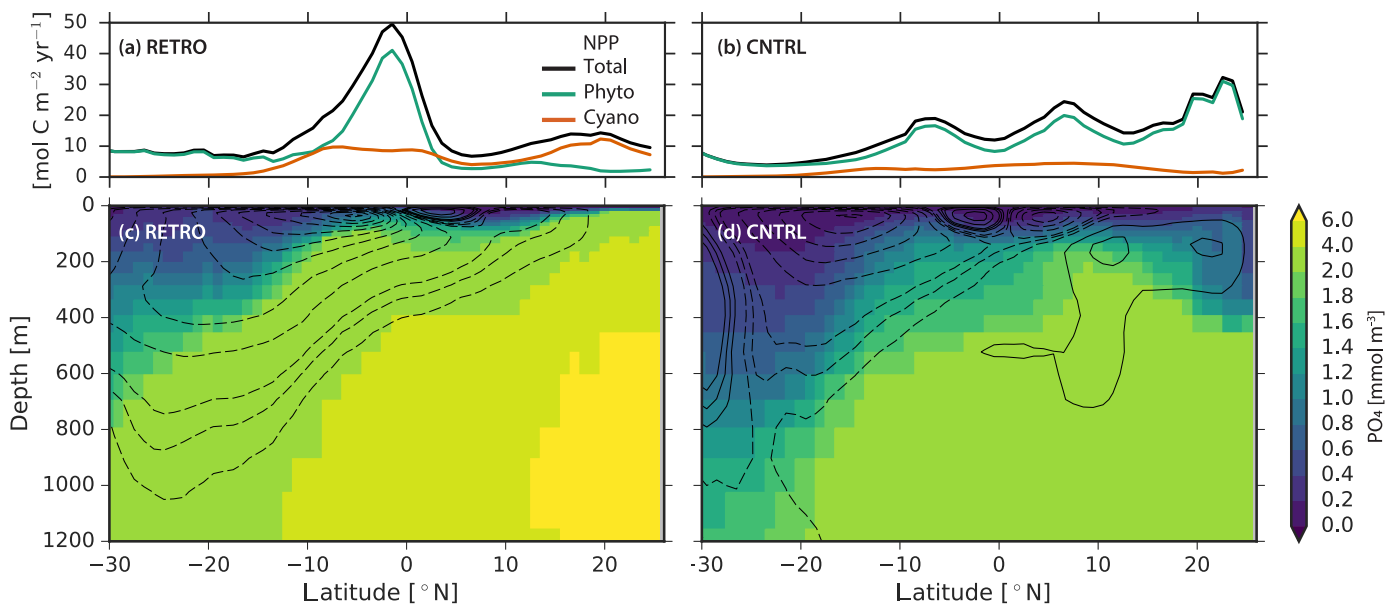

Figure 17. Zonal means in the Indian Ocean for RETRO (a, c) and CNTRL (b, d): net primary production $\left(\mathrm{NPP}, \mathbf{a}, \mathbf{b}, \mathrm{black}^{\mathrm{m}}, \mathrm{mol} \mathrm{C} \mathrm{m}^{-2} \mathrm{yr}^{-1}\right)$ with contributions of bulk phytoplankton (green) and cyanobacteria (red); phosphate concentration $(\mathbf{c}, \mathbf{d})\left(\mathrm{mmol} \mathrm{m}^{-3}\right)$. Contours of MOC are overlaid at levels of $\pm 1,2$, and multiples of $3 \mathrm{~Sv}$.

timescales, at how the ocean responds to the sense of planetary rotation.

Overall, differences in global and zonal mean quantities between RETRO and CNTRL are small, indicating that these quantities are rather robust features of the Earth's climate and do not depend on the sense of rotation. Hemispheric asymmetries consistent in both simulations seem to depend on the land-sea distribution rather than on the atmospheric or oceanic circulation. Longitudinal differences between these experiments, while considerable, are for the most part as one would have expected given a basic understanding of climate physics proposed by von Humboldt and Köppen. The zonal wind patterns reverse in RETRO relative to $\mathrm{CN}$ TRL, which results in midlatitude easterlies instead of westerlies, and tropical westerlies (and trades) instead of easterlies. Due to the reversed winds in RETRO, subtropical and midlatitude continents become colder on their western coasts and warmer in the east. Temperature changes over Eurasia are especially prominent with a strong wintertime cooling over northwestern Europe ( $>20 \mathrm{~K}$ ). The continental climates show shifts in isotherms consistent with expectations dating back to von Humboldt's ideas now more than 200 years old.
Changes in climate zones are in broad agreement with the predictions made by Köppen nearly one century ago. For instance, deserts shift from the western subtropical continental boundaries to the southeast. In the ocean, the western boundary currents show up as eastern boundary currents in RETRO, associated with a strong poleward heat transport in the subtropics, which is also to be expected from classical oceanographic theory. The classical theories explain many features of the climate, as is indicated by their success in predicting many of the simulated climate changes in RETRO.

However, not all of the changes were expected from classical theories, nor necessarily trivial. One of the most unexpected differences is in patterns of precipitation. In the extratropics, storms show greatest track densities over land, rather than over the ocean, even if the intensity and number of storms do not show detectable changes. Likewise, there is a northward shift of the extratropical storms and the main regions of baroclinicity. Over North America, a major storm track develops to the north of the Great Lakes. Cyclones transport moisture from south Asia and the Indian Ocean towards the Mediterranean and the Atlantic. 

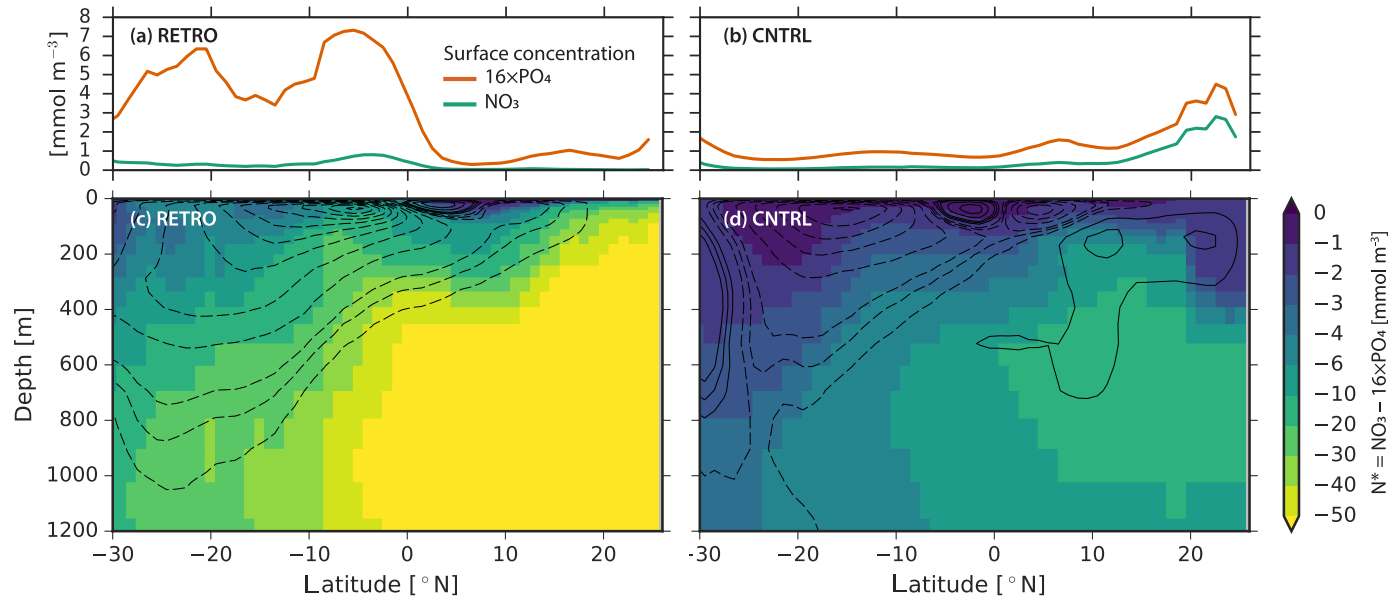

Figure 18. Zonal means in the Indian Ocean for RETRO $(\mathbf{a}, \mathbf{c})$ and CNTRL $(\mathbf{b}, \mathbf{d})$ : nitrate (green) and phosphate $(\cdot 16$, red) concentrations $(\mathbf{a}, \mathbf{b})\left(\mathrm{mmol} \mathrm{m}{ }^{-3}\right)$, and $\mathrm{N}^{*}=\mathrm{NO}_{3}-16 \cdot \mathrm{PO}_{4}(\mathbf{c}, \mathbf{d})$ in the Indian Ocean. Contours of MOC are overlaid at levels of $\pm 1,2$, and multiples of $3 \mathrm{~Sv}$.

In the tropics, the rainbands shift from a double ITCZ centered in and around the warm-pool Asian-Australian monsoon complex in CNTRL, to a more tripolar structure with centers of action in the eastern tropical Atlantic, the central Pacific, and a monsoon region centered in the Middle East. A southward shift in the position of the annually and zonally averaged position of the rain bands is consistent with shifts in the zero line of the atmospheric energy transport (the ITCZ). The shift in this line is as would be anticipated by changes in the global climate, i.e., from a warming of the tropics or increased Northern Hemisphere baroclinicity (Kang et al., 2008; Bischoff and Schneider, 2014). The origin of these changes is, however, not clear as the magnitude and position of the rainband shifts do not agree quantitatively with changes in the energy flux near the Equator. The latter suggests that stationary eddy transport and air-sea interaction (Wallace et al., 1989; Philander et al., 1996) are important for determining the position of the zonally and annually averaged rainbands.

Another unexpected change, albeit one in line with the changes in patterns of precipitation, is a shift in the desert climates from the Northern Hemisphere to the Southern Hemisphere. The simulations predict a complete replacement of the wide desert belt from west Africa to the Middle East in CNTRL by more moderate, humid climates in RETRO. This retreat of desert climates in Africa and Eurasia is accompanied by an extensive formation of dry climates in South America and North America but not so dry as the African dry climates they replace. Hence, Earth becomes greener in RETRO with more biomass. Changes in biomass and precipitation patterns are to the first order consistent with the Americas adopting the climate pattern of present-day Europe/Africa, and vice versa.

The exchange of European-African with North-South American climate and the shifts in fresh water transport by the atmospheric circulation are accompanied by large changes in the ocean overturning circulations. An important and outstanding question of physical oceanography is why the North Atlantic is so disproportionate in its production of deep water, with very little or no deep water formed in the North Pacific. Kamphuis et al. (2011) suggested that the more southward continental boundary of the Pacific limits deep water formation as compared to the Atlantic, which extends well into the Arctic. Other studies (e.g., Warren, 1983) have suggested that the freshening of the Pacific relative to the Atlantic stabilizes the overturning pattern. A prominent difference between RETRO and CNTRL is the collapse of the Atlantic MOC in RETRO, with only sporadic formation of deep intermediate water in the North Atlantic. At the same time, a strong meridional overturning cell emerges in the Pacific. The Pacific MOC in RETRO is similar in structure but slightly stronger than the Atlantic MOC in CNTRL. The breakdown of the Atlantic MOC and the associated decrease in meridional heat transport leads to a cooling of the North Atlantic associated with a southward extension of sea ice and a significant cooling over Europe. The accompanying southward shift of the temperature maximum over the tropical Atlantic contributes to the southward shift of the Atlantic ITCZ, through enhanced baroclinicity (and hence heat transport) as argued above. In contrast, the Pacific MOC in RETRO, characterized by an enhanced northward transport of heat along the west coast of North America, results in a significant warming of the North Pacific. The switch of the deep water formation into the North Pacific shows that changes in atmospheric circulation and moisture transport are sufficient to create a completely reversed conveyor belt circulation. The topographic setting (basin and continent distribution) does not restrict deep water formation to the North Atlantic and Southern Ocean, while preventing it in the North Pacific, contradicting findings from Kamphuis et al. (2011). 
In the tropics, the Indian Ocean takes over the role of the eastern tropical Pacific with a strong net heat uptake due to strong upwelling. The patterns of biogeochemical tracers are tightly bound to changes in the ocean circulation. Zonal and global means of biogeochemical features are very similar in CNTRL and RETRO. However, an unforeseen shift in the dominance of cyanobacteria over bulk phytoplankton is found in the northern part of the Indian Ocean. Here, the interplay between strong upwelling and basin geometry leads to the development of an extended oxygen minimum zone with increased denitrification and nutrient trapping. Upwelling of phosphate-enriched and nitrate-depleted water leads to favorable growth conditions for cyanobacteria.

Changes in the carbon inventory of the terrestrial and the marine realm in RETRO are rather small. The global carbon storage on land increases by $86 \mathrm{PgC}$; the marine carbon inventory increases by $\sim 100 \mathrm{PgC}$, both compared to CNTRL. The increase in carbon storage of both subsystems is only possible due to the constant prescribed atmospheric $\mathrm{CO}_{2}$ concentration acting as an unlimited carbon source. With a fully coupled carbon cycle, an increase of the land carbon inventory would tend to reduce the atmospheric $\mathrm{CO}_{2}$ which would lead to a compensating effect (outgassing) by the ocean. The projected change on land (increase by $\sim 86 \mathrm{Pg} \mathrm{C}$ ) is rather small compared to the marine carbon inventory $(\sim 38000 \mathrm{PgC})$. When taking characteristics of the marine carbon chemistry and the long simulation period into account, the ocean is able to compensate for most (more than $80 \%$; Archer et al., 2009) of the additional carbon stored on land in RETRO. Thus, we expect the effective change of the atmospheric $\mathrm{CO}_{2}$ in a fully coupled simulation to be smaller than 7-8 ppmV. Such a change in atmospheric $\mathrm{CO}_{2}$ would have only minor effects on climate.
Sensitivity studies suggest that differences in the circulation in the RETRO versus CNTRL simulations do not fundamentally affect Earth's climate sensitivity compared to, e.g., the effect of model resolution. Changes in the ocean in RETRO do, however, appear to affect the timescale of equilibration.

Overall, changes in the interaction between the atmosphere and the ocean that accompany a reversal of the sense of planetary rotation help demonstrate the important role of the ocean in climate and provide valuable out-ofsample tests of the robustness of climate models and the physics governing their response to perturbations. Repeating the RETRO/CNTRL pair of simulations at higher resolutions and with other models could thereby provide a fascinating laboratory for testing understanding of climate models and, by inference, of Earth's climate.

Code availability. MPI-ESM is available under the Software License Agreement version 2, after acceptance of a license (https: //www.mpimet.mpg.de/en/science/models/license/; MPI, 2018).

Data availability. Data are available from https://cera-www. dkrz.de/WDCC/ui/cerasearch/entry?acronym=DKRZ_LTA_110_ ds00001; (WDC Climate, 2018). 


\section{Appendix A: Changes in the El Niño-Southern Oscillation}

The analysis of the geographical distribution of the climate mean surface temperature (Fig. 2, described in Sect. 3) is extended by a variability analysis focusing on the tropical Indian-Pacific Ocean $\left(30^{\circ} \mathrm{S}-30^{\circ} \mathrm{N}, 40^{\circ} \mathrm{E}-60^{\circ} \mathrm{W}\right)$ to capture El Niño-Southern Oscillation (ENSO)-related year-to-year fluctuations (deviations from the climate mean; Fig. A1) for RETRO and CNTRL.

Figure A1 shows the two leading empirical orthogonal functions (EOFs) which cover the area from the east African to the South American coast $\left(30^{\circ} \mathrm{S}-30^{\circ} \mathrm{N}, 40^{\circ} \mathrm{E}-60^{\circ} \mathrm{W}\right)$. The two leading EOFs explain $36 \%$ and $14 \%$ of the total variance for RETRO (62\% and $10 \%$ for CNTRL). The dominating variability is centered in the Indian Ocean (tropical Pacific for CNTRL). The second EOF captures variability in the western tropical Pacific.

The sectional seasonality of the sea surface temperature anomaly (SSTA, averaged between $5^{\circ} \mathrm{S}$ and $5^{\circ} \mathrm{N}$ ) is diagnosed in terms of the monthly standard deviation after removing the climatological annual cycle (Fig. A2). In CNTRL, the strongest variability, which occurs in the eastern tropical Pacific in July-August, is different from the observed ENSO peaking in boreal winter months, but the weak variability that characterizes the spring predictability barrier is clearly seen (Fig. A2). In RETRO, the center of strong variability shifts to the Indian Ocean and to the middle tropical Pacific with peaks in May-July and around OctoberNovember, respectively.
The seasonal cycle of the variability of the indices characterizing only the Indian Ocean (INDINO) $\left(10\right.$ to $0^{\circ} \mathrm{S}$ for RETRO) and the tropical Pacific Niño4 (for CNTRL) as well as the spectral densities of these indices are shown in Fig. A3. While the Niño3/4 index reveals a broad peak in the 1- to 10 -year period domain, the lower frequency variability in the INDINO index levels off as white noise. Additional diagnostics on the physical causes of the variability behavior and the atmospheric long-distance teleconnections are beyond the scope of this analysis.
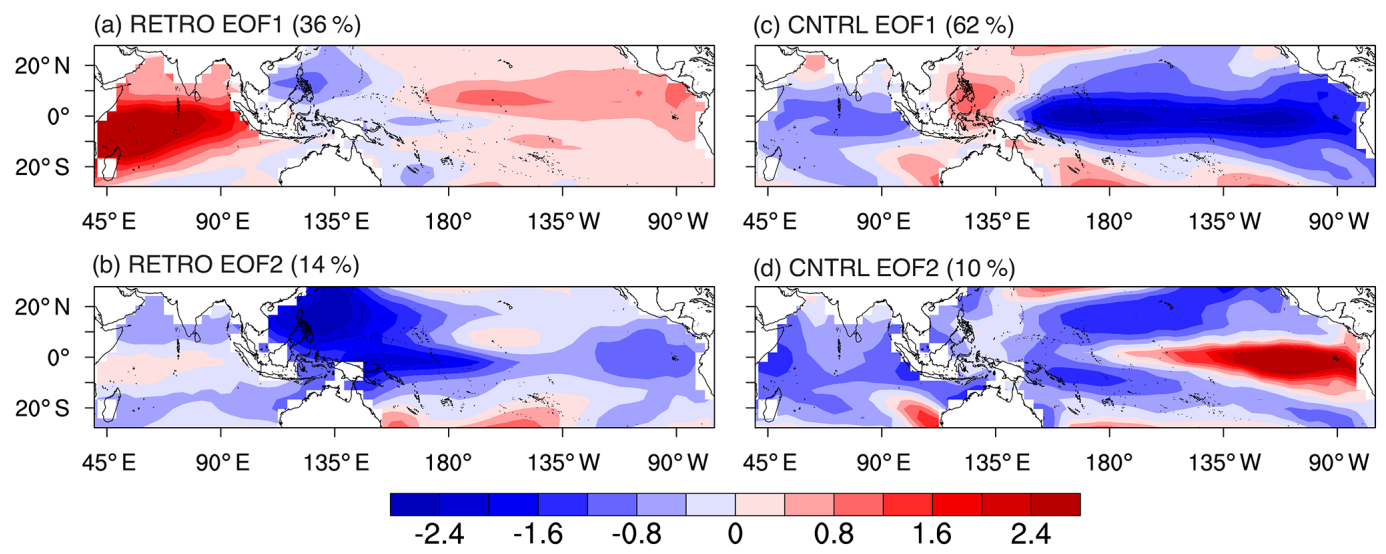

(d) CNTRL EOF2 (10\%)

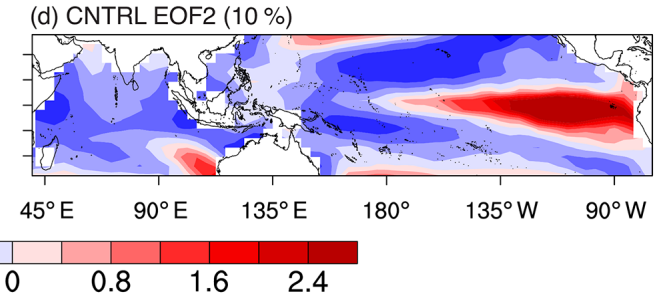

Figure A1. Two leading EOFs of yearly SST anomaly $\left(30^{\circ} \mathrm{S}-30^{\circ} \mathrm{N}, 40^{\circ} \mathrm{E}-60^{\circ} \mathrm{W}\right)$ : RETRO (a, b) and CNTRL (c, d). 

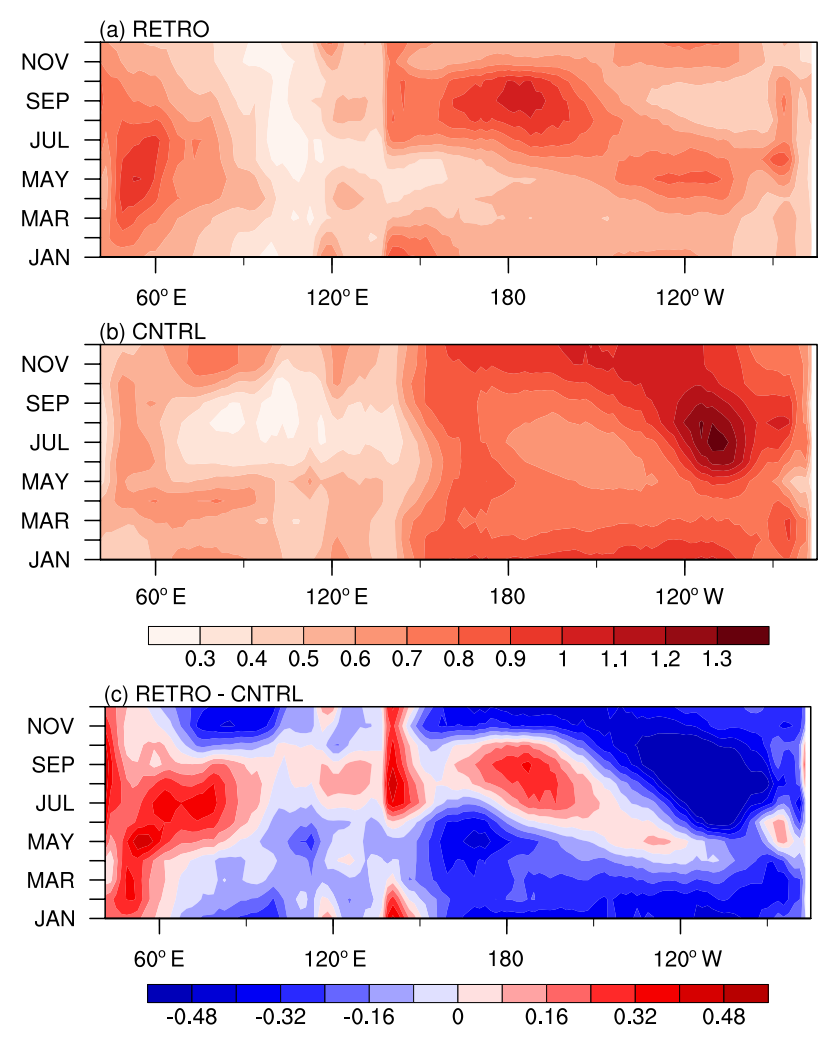

Figure A2. Sectional view of the seasonality of the sea surface temperature anomaly (SSTA) at the Equator (averaged between $5^{\circ} \mathrm{S}$ and $5^{\circ} \mathrm{N}$ ) diagnosed as monthly deviation from the climatological annual cycle: (a) RETRO, (b) CNTRL, and (c) RETRO-CNTRL.
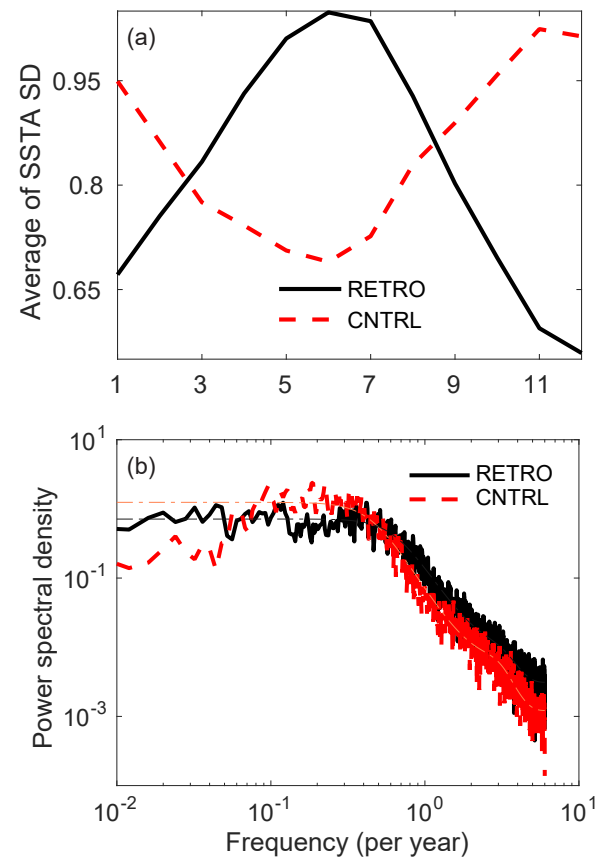

Figure A3. SSTA indices: (a) seasonality of Niño3.4 (CNTRL, black) and INDINO (RETRO, averaged over $10-0^{\circ} \mathrm{S}, 50-70^{\circ} \mathrm{E}$; red), and (b) the respective power spectra. 

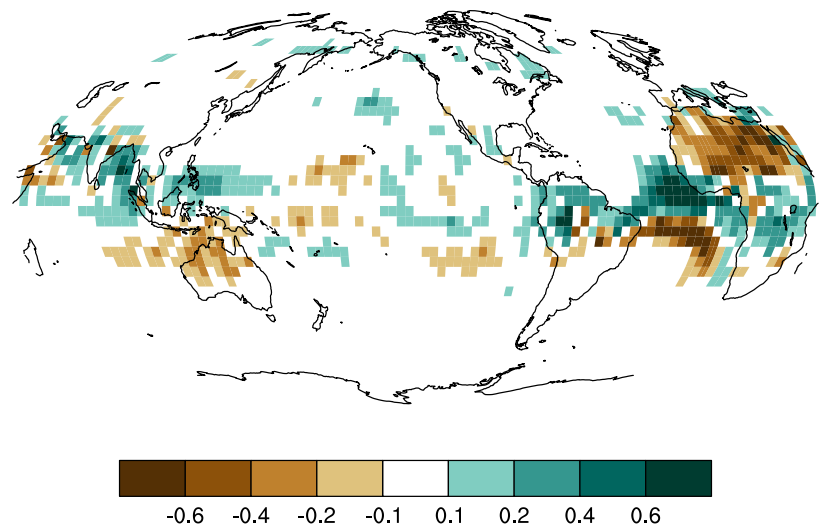

Figure B1. Mean precipitation difference $\left(\mathrm{mm} \mathrm{day}^{-1}\right)$ between RETRO-S and RETRO. Note the different color scale when comparing to Fig. 2.

\section{Appendix B: Influence of the direction of the movement of the Sun}

Presumably, climate changes simulated in RETRO are due to the differences arising from differences in the sign of the planetary vorticity, as imparted by the Coriolis force acting on the wind. But changing the sense of planetary rotation also changes the diurnal march of the land under the Sun. To understand the extent to which these thermodynamic effects influence the differences between RETRO and CNTRL, one additional 6990-year long simulation (RETRO-S) was performed without changing the sense of diurnal march in insolation. Thus, all changes in this simulation relative to CNTRL are due to the reversal of the sign of the Coriolis parameter. Comparison with RETRO isolates the effect of a reversed path of the surface under the Sun. Differences between RETRO-S and RETRO are for the most part negligible, and only evident in the distribution of precipitation. Over Africa, RETRO-S precipitates $0.5 \mathrm{~mm} \mathrm{day}^{-1}$ less than RETRO (see Fig. B1), a difference that is in the order of the year-to-year variability, as measured by the standard deviation of annual mean precipitation. Likely as a consequence of this change, RETRO-S also exhibits a clear northward shift of the ITCZ over the tropical Atlantic Ocean.

To understand this difference, we look at the diurnal cycle of precipitation (not shown) over the impacted land masses. In agreement with the Sun movement, precipitation starts falling on the eastern side of Africa in RETRO-S and moves inland. The opposite is true in RETRO, so that precipitation starts falling with a $2-4 \mathrm{~h}$ time lag on the eastern side of Africa (note that the output frequency is $2 \mathrm{~h}$ ). Despite the later precipitation start, RETRO produces more precipitation. This may be related to the fact that most precipitation falls on the eastern side of Africa in the mean (see Fig. 1), with a background flow over the continent that is directed eastwards. Hence, in RETRO, the propagation of the convection due to the Sun movement and the background flow work together, whereas in RETRO-S they are opposed to each other. The complementary situation happens on the western side of South America. Here, the background flow is westward, which should lead to an enhancement of precipitation in RETRO-S, which is indeed the case, as shown in Fig. B1.

\section{Appendix C: Climate sensitivity}

If climate sensitivity, the long-term response to increased atmospheric $\mathrm{CO}_{2}$, did not depend on the details of the circulation, we would expect it not to depend on the direction of the planetary rotation. To investigate this, we conduct two experiments with abrupt quadrupling of atmospheric $\mathrm{CO}_{2}$ concentration (RETROx4 and CNTRLx4; Fig. C1). Here, the equilibrium response is estimated using linear regression on annual means of the relationship between radiation balance and global warming. The slope in such a diagram is thought of as a feedback parameter, $\lambda$, which must be negative to yield a stable climate. We find, indeed, that the climate sensitivity is not very different between CNTRLx 4 and RETROx4, roughly $10 \%$ larger in the latter $(4.00$ versus $4.45 \mathrm{~K}$ per doubling of $\mathrm{CO}_{2}$ ). This is substantially less than the difference to the slightly higher-resolution MPI-ESM1.2-LR model (also shown, $3.19 \mathrm{~K}$ ) and much less than the spread among CMIP5 climate models (2.0-4.6 K) and scientific uncertainty as expressed by the likely range from the IPCC AR5 $(1.5-4.5 \mathrm{~K})$. It should be noted that the here-reported climate sensitivities are regressed over years 21-1000. Using instead the more standard regression over years $1-150$, we obtain 3.46, 3.92, and $2.87 \mathrm{~K}$ for CNTRLx4, RETROx4, and MPI-ESM1.2-LR.

The small increase in the long-term feedback parameter for RETROx 4 of about $\delta \lambda \approx+0.09 \mathrm{~W} \mathrm{~m}^{-2} \mathrm{~K}^{-1}$ stems primarily from cloud shortwave effects. Indeed, it was tempting to think that the more widespread sea-ice cover in the North Atlantic in RETRO would cause a stronger surface albedo feedback, but the clear-sky shortwave component does not differ between the simulations. Likewise, the longwave feedbacks differ by merely $0.01 \mathrm{~W} \mathrm{~m}^{-2} \mathrm{~K}^{-1}$. Thus, the remaining $0.08 \mathrm{~W} \mathrm{~m}^{-2} \mathrm{~K}^{-1}$ stems from cloud shortwave feedbacks.

The difference in feedback parameter between the earlier parts of the simulation (years 1-20) and later parts (years 211000 ) is thought to be due to tropical cloud feedbacks (Block and Mauritsen, 2013; Andrews et al., 2015; Zhou et al., 2016). One idea is that surface temperatures in the ocean upwelling regions in the tropical east Pacific warm slower than the surface waters in the warm-pool region, causing more low-level cloudiness in the east as a result of increasing low-level stratification. The striking similarity between CNTRLX 4 and RETROx4 is suggestive that the details of the tropical atmosphere and ocean circulations also do not matter for determining the strength of this mechanism. 


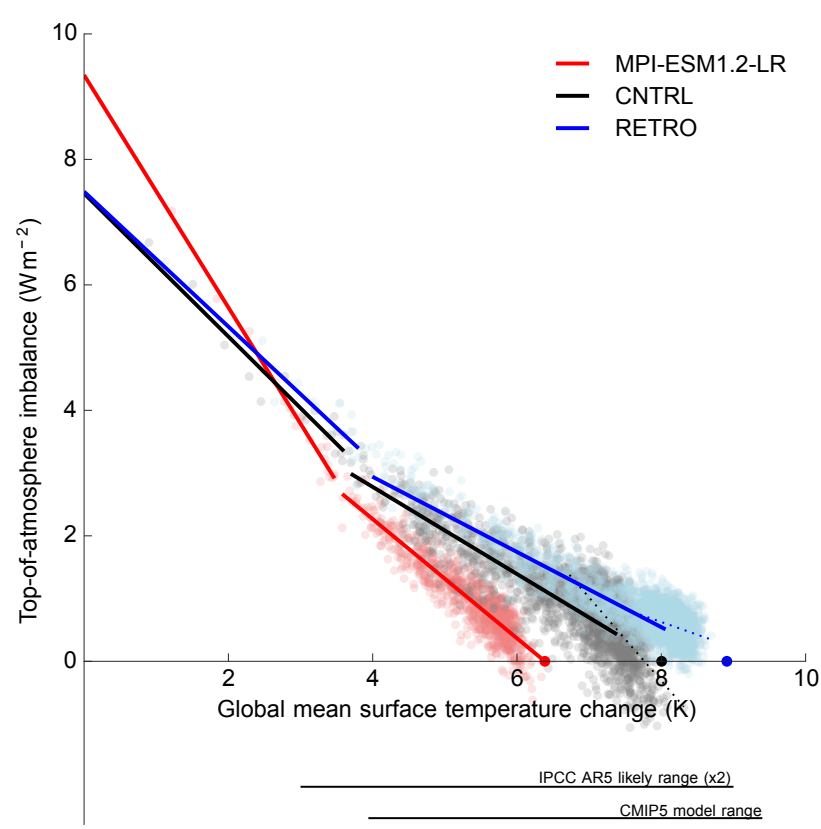

Figure C1. Surface temperature change versus top-of-atmosphere energy imbalance for RETROx4 and CNTRLx4 each run for 2500 years following an abrupt quadrupling of atmospheric $\mathrm{CO}_{2}$. Small dots are annual means. For comparison, a 1000-year run with MPI-ESM1.2-LR, i.e., a higher-resolution version than CNTRL, is shown. The lines are linear regressions over years 1-20 and 211000 , respectively, and the solid dots on the $x$ axis shows the linear extrapolation to stationarity based on the year 21-1000 regressions. Also shown for CNTRLx4 and RETROx4 as dotted lines are the regressions for years 1001-2500. The lines in the lower part of the figure show the IPCC AR5 assessed likely $(p>0.66)$ range as well as the range of responses found in CMIP5 climate models.

Finally, we noted a striking difference between CNTRLx 4 and RETROx4 in the long-term equilibration for years 10012500. As found for an earlier version of the model by $\mathrm{Li}$ et al. (2013), CNTRLx4 exhibits a third timescale where $\lambda$ becomes more negative, causing the system to equilibrate faster, whereas, if anything, RETROx4 does the opposite. The third timescale found in CNTRL and in the ECHAM5/MPIOM model used by Li et al. (2013) is yet to be found in other models partly because models are only seldom run long enough. Previously, we thought the behavior originated in the coarse resolutions used in these runs, as the MPI-ESM1.2-LR, exhibits a faster equilibration, but the contrasting very slow equilibration of the coarse-resolution RETRO simulation could indicate that the properties of the ocean circulation are indeed important for the equilibration process.

\section{Appendix D: Iron supply in marine biogeochemistry}

To assess the contribution of aeolian iron input into the northern Indian Ocean to the growth of cyanobacteria, we es-
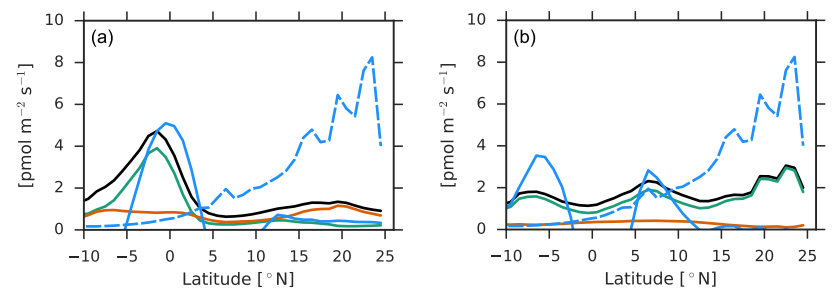

Figure D1. Zonal means in the Indian Ocean for RETRO (a) and CNTRL (b) of iron demand for net primary production (all phytoplankton: black, bulk phytoplankton: green, cyanobacteria: red), aeolian iron input (dashed blue), and iron flux due to upwelling (solid blue). All fluxes are given in pmol Fe $\mathrm{m}^{-2} \mathrm{~s}^{-1}$.

timated the minimal iron flux into the upper $55 \mathrm{~m}$ due to upwelling (Fig. D1). One of the characteristics of the marine iron cycle is that iron concentrations in the deep ocean are almost constant $\left(0.6-0.8 \mu \mathrm{mol} \mathrm{Fe} \mathrm{m}{ }^{-3}\right.$ for the Atlantic and Pacific; Moore and Braucher, 2008). When multiplying the upwelling velocity at $55 \mathrm{~m}$ water depth of RETRO with this background concentration (set to $0.6 \mu \mathrm{mol} \mathrm{Fe} \mathrm{m}{ }^{-3}$ in HAMOCC), we achieve the lowest estimate of the iron supply due to circulation. For comparison, we calculate the iron demand for net primary production of bulk phytoplankton and cyanobacteria. As both phytoplankton types contain carbon and iron at the same ratio in our model, the latitudinal structure of the zonal mean iron demand is identical to that of the zonal mean net primary production shown in Fig. 17. Even this lower bound estimate of the iron upwelling flux satisfies $40 \%-80 \%$ of the iron demand of cyanobacteria in the northern Indian Ocean. It is likely that seawater concentrations of iron in the upwelling waters are higher than the background value even without local aeolian input. The cause for this is the interplay between the high primary production/remineralization at the Equator, which leads to an accumulation of nutrients (phosphate and iron) in the upper ocean and the meridional overturning circulation (Fig. 17) that creates a northward transport. The lack of nitrate (Fig. 18) in these upwelling waters inhibits growth of bulk phytoplankton fostering the local dominance of cyanobacteria.

\section{Appendix E: Storm track changes}

In this section, additional results expanding on the tracking of cyclones in the Northern Hemisphere during boreal winter (DJF; Sect. 3), as well as the analysis for the Southern Hemisphere during austral winter (JJA) are presented. Figure E1 shows the zonal averaged statistics of cyclones tracked in the Northern Hemisphere.

Results show that, while the storm tracks shift from the ocean to the land (Fig. 4), there is little difference in the zonal mean statistics between RETRO and CNTRL besides the baroclinic growth rate. 
In the Southern Hemisphere, cyclones shift from the Indian and Atlantic oceans to the Pacific Ocean, as presented in Fig. E2.
Consistent with that, the cyclones in the Pacific Ocean in the retrograde planet are stronger, have higher growth rates, and are also faster (Fig. E3). However, these local changes are compensated such that the overall zonally averaged statistics in the Southern Hemisphere do not change significantly (not shown).

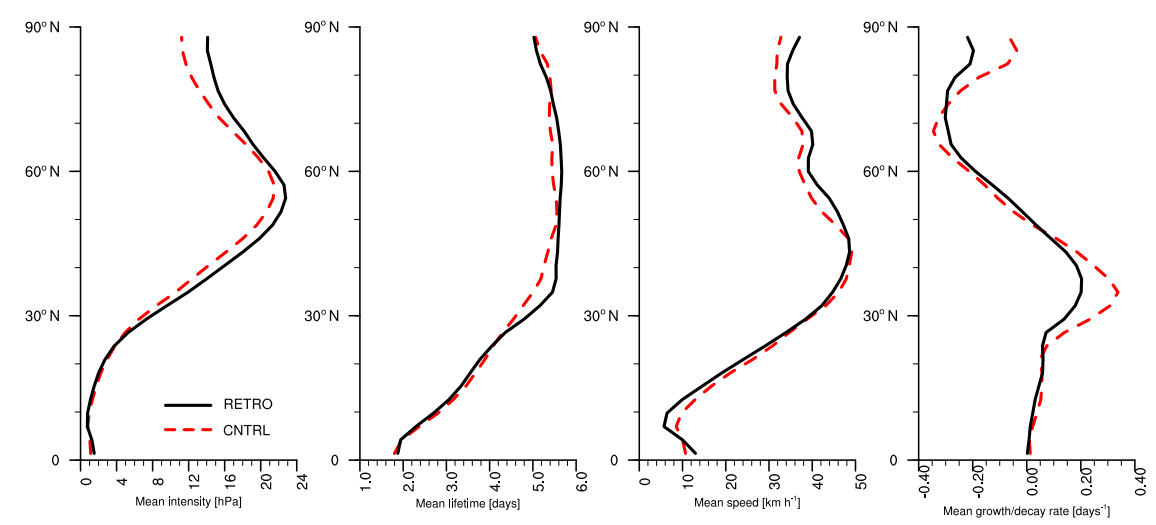

Figure E1. Zonal averaged statistics obtained from the tracking algorithm for the DJF season in the Northern Hemisphere.
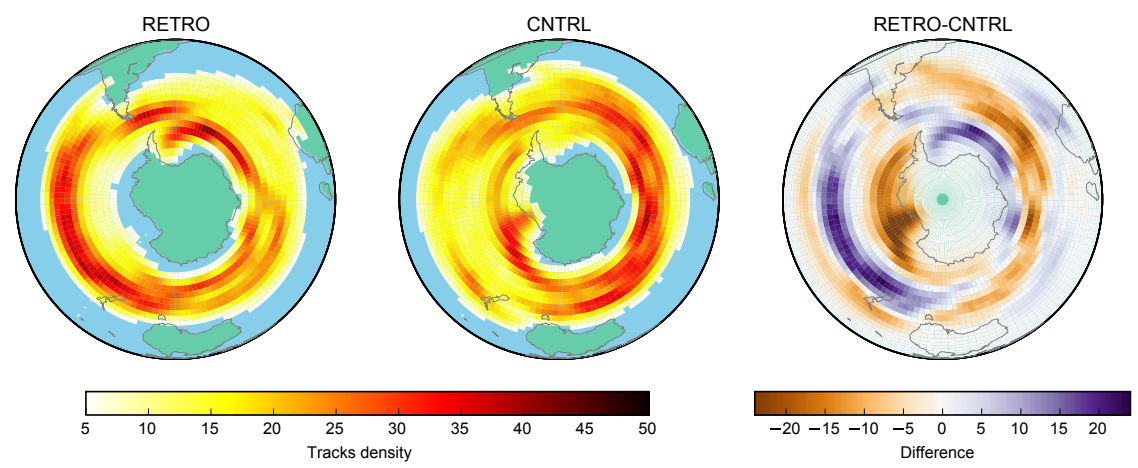

Figure E2. As in Fig. 4 but for the Southern Hemisphere during the JJA season.
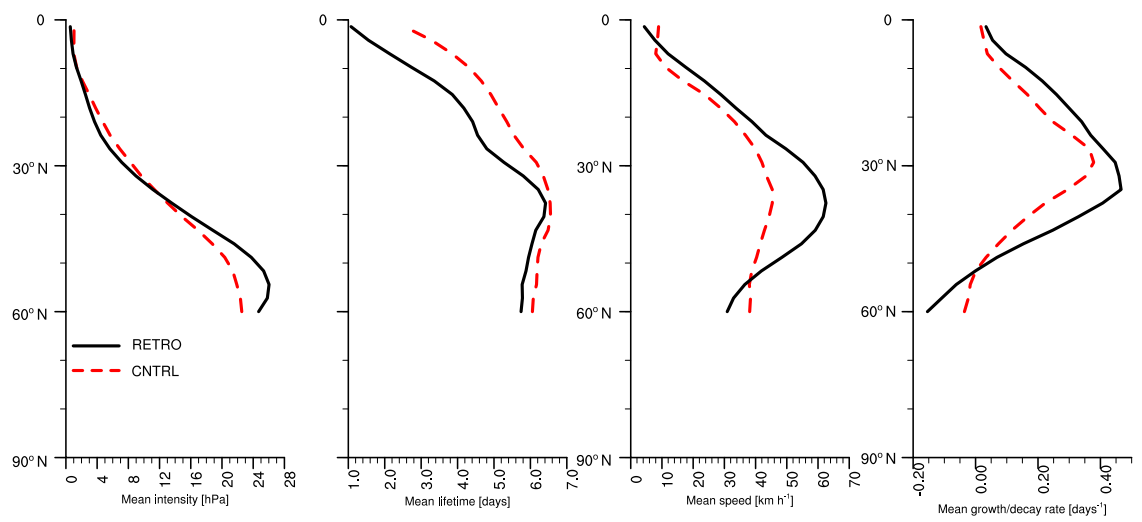

Figure E3. Zonal averaged statistics obtained from the tracking algorithm for the JJA season in the Southern Hemisphere Pacific Ocean region. 
Author contributions. BS had the original idea; UM designed and performed the experiments; all authors wrote the paper.

Competing interests. The authors declare that they have no conflict of interest.

Acknowledgements. This work was in part supported by German Federal Ministry of Education and Research (BMBF) as Research for Sustainability initiative (FONA) through the project PalMod (FKZ: 01LP1502A and 01LP1504C). All simulations were performed at the German Climate Computing Center (DKRZ). Norbert Noreiks created the Köppen turnip plot in Fig. 9. Finally, we thank two anonymous reviewers and Daniel Kirk-Davidoff, who helped to significantly improve the manuscript.

The article processing charges for this open-access publication were covered by the Max Planck Society.

Edited by: Daniel Kirk-Davidoff

Reviewed by: two anonymous referees

\section{References}

Andrews, T., Gregory, J. M., and Webb, M. J.: The Dependence of Radiative Forcing and Feedback on Evolving Patterns of Surface Temperature Change in Climate Models, J. Climate, 28, 16301648, https://doi.org/10.1175/jcli-d-14-00545.1, 2015.

Archer, D., Eby, M., Brovkin, V., Ridgwell, A., Cao, L., Mikolajewicz, U., Caldeira, K., Matsumoto, K., Munhoven, G., Montenegro, A., and Tokos, K.: Atmospheric Lifetime of Fossil Fuel Carbon Dioxide, Annu. Rev. Earth Planet. Sci., 37, 117-134, https://doi.org/10.1146/annurev.earth.031208.100206, 2009.

Bathiany, S., Claussen, M., Brovkin, V., Raddatz, T., and Gayler, V.: Combined biogeophysical and biogeochemical effects of largescale forest cover changes in the MPI earth system model, Biogeosciences, 7, 1383-1399, https://doi.org/10.5194/bg-7-13832010, 2010.

Bischoff, T. and Schneider, T.: Energetic Constraints on the Position of the Intertropical Convergence Zone, J. Climate, 27, 49374951, 2014.

Block, K. and Mauritsen, T.: Forcing and feedback in the MPI-ESM-LR coupled model under abruptly quadrupled $\mathrm{CO}_{2}$, J. Adv. Model. Earth Syst., 5, 676-691, https://doi.org/10.1002/jame.20041, 2013.

Breitbarth, E., Oschlies, A., and LaRoche, J.: Physiological constraints on the global distribution of Trichodesmium - effect of temperature on diazotrophy, Biogeosciences, 4, 53-61, https://doi.org/10.5194/bg-4-53-2007, 2007.

Broecker, W.: The great ocean conveyor, Oceanography, 4, 79-89, 1991.

Broecker, W.: Thermohaline circulation, the Achilles heel of our climate system: Will man-made $\mathrm{CO}_{2}$ upset the current balance?, Science, 278, 1582-1588, https://doi.org/10.1126/science.278.5343.1582, 1997.

Chiang, J. C. H., Biasutti, M., and Battisti, D. S.: Sensitivity of the Atlantic Intertropical Convergence Zone to Last Glacial
Maximum boundary conditions, Paleoceanography, 18, 1094, https://doi.org/10.1029/2003PA000916, 2003.

Claussen, M.: Late Quaternary vegetation-climate feedbacks, Clim. Past, 5, 203-216, https://doi.org/10.5194/cp-5-203-2009, 2009.

Eyring, V., Bony, S., Meehl, G. A., Senior, C. A., Stevens, B., Stouffer, R. J., and Taylor, K. E.: Overview of the Coupled Model Intercomparison Project Phase 6 (CMIP6) experimental design and organization, Geosci. Model Dev., 9, 1937-1958, https://doi.org/10.5194/gmd-9-1937-2016, 2016.

Frierson, D. M. W., Hwang, Y.-T., Fučkar, N. S., Seager, R., Kang, S. M., Donohoe, A., Maroon, E. A., Liu, X., and Battisti, D. S.: Contribution of ocean overturning circulation to tropical rainfall peak in the Northern Hemisphere, Nat. Geosci., 6, 940-944, 2013.

Giorgetta, M., Roeckner, E., Mauritsen, T., Bader, J., Crueger, T. M. E., Rast, S., Kornblueh, L., Schmidt, H., Kinne, S., Hohenegger, C., Möbis, B., Krismer, T., Wieners, K.-H., and Stevens, B.: The atmospheric general circulation model ECHAM6 - Model description, Tech. Rep. 135, Max-Planck-Institut für Meteorologie, Hamburg, https://doi.org/10.17617/2.1810480, 2013.

Hadley, G.: Concerning the cause of the general trade-winds: By Geo. Hadley, Esq; FRS, The Royal Society Publishing, 39, 5862, https://doi.org/10.1098/rstl.1735.0014, 1735.

Hoskins, B. J. and Hodges, K. I.: New perspectives on the Northern Hemisphere winter storm tracks, J. Atmos. Sci., 59, 1041-1061, 2002.

Hutchins, D. A. and Fu, F.: Microorganisms and ocean global change, Nat. Microbiol., 2, 17058, https://doi.org/10.1038/nmicrobiol.2017.58, 2017.

Ilyina, T., Six, K., Segschneider, J., Maier-Reimer, E., Li, H., and Nunez-Riboni, I.: Global ocean biogeochemistry model HAMOCC: Model architecture and performance as component of the MPI-Earth System Model in different CMIP5 experimental realizations, J. Adv. Model. Earth Syst., 5, 1-29, https://doi.org/10.1029/2012MS000178, 2013.

Jungclaus, J. H., Fischer, N., Haak, H., Lohmann, K., Marotzke, J., Matei, D., Mikolajewicz, U., Notz, D., and von Storch, J. S.: Characteristics of the ocean simulations in the Max Planck Institute Ocean Model (MPIOM) the ocean component of the MPIEarth system model, J. Adv. Model. Earth Syst., 5, 422-446, https://doi.org/10.1002/jame.20023, 2013.

Kamphuis, V., Huisman, S. E., and Dijkstra, H. A.: The global ocean circulation on a retrograde rotating earth, Clim. Past, 7, 487-499, https://doi.org/10.5194/cp-7-487-2011, 2011.

Kang, S. M., Held, I. M., Frierson, D. M. W., and Zhao, M.: The Response of the ITCZ to Extratropical Thermal Forcing: Idealized Slab-Ocean Experiments with a GCM, J. Climate, 21, 35213532, 2008.

Kang, S. M., Frierson, D. M. W., and Held, I. M.: The Tropical Response to Extratropical Thermal Forcing in an Idealized GCM: The Importance of Radiative Feedbacks and Convective Parameterization, J. Atmos. Sci., 66, 2812-2827, 2009.

Kaspi, Y. and Schneider, T.: Winter cold of eastern continental boundaries induced by warm ocean waters, Nature, 471, 621624, 2011.

Keith, D. W.: Meridional energy transport: uncertainty in zonal means, Tellus A, 47, 30-44, https://doi.org/10.3402/tellusa.v47i1.11492, 1995. 
Köppen, W.: Die Klimate der Erde: Grundriss der Klimakunde, Walter de Gruyter \& Company, Berlin, 1923.

Li, C., von Storch, J.-S., and Marotzke, J.: Deep-ocean heat uptake and equilibrium climate response, Clim. Dynam., 40, 10711086, https://doi.org/10.1007/s00382-012-1350-z, 2013.

Mauritsen, T., Bader, J., Becker, T., Behrens, J., Bittner, M., Brokopf, R., Brovkin, V., Claussen, M., Crueger, T., Esch, M., Fast, I., Fiedler, S., Popke, D., Gayler, V., Giorgetta, M., Goll, D., Haak, H., Hagemann, S., Hedemann, C., Hohenegger, C., Ilyina, T., Jahns, T., Jimenez Cuesta de la Otero, D., Jungclaus, J., Kleinen, T., Kloster, S., Kracher, D., Kinne, S., Kleberg, D., Lasslop, G., Kornblueh, L., Marotzke, J., Matei, D., Meraner, K., Mikolajewicz, U., Modali, K., Möbis, B., Müller, W., Nabel, J., Nam, C., Notz, D., Nyawira, S., Paulsen, H., Peters, K., Pincus, R., Pohlmann, H., Pongratz, J., Popp, M., Raddatz, T., Rast, S., Redler, R., Reick, C., Rohrschneider, T., Schemann, V., Schmidt, H., Schnur, R., Schulzweida, U., Six, K., Stein, L., Stemmler, I., Stevens, B., von Storch, J., Tian, F., Voigt, A., de Vrese, P., Wieners, K.-H., Wilkenskjeld, S., Roeckner, E., and Winkler, A.: Developments in the MPI-M Earth System Model version 1.2 (MPI-ESM1.2) and its response to increasing $\mathrm{CO}_{2}, \mathrm{~J}$. Adv. Model. Earth Syst., in review, 2018.

Moore, J. K. and Braucher, O.: Sedimentary and mineral dust sources of dissolved iron to the world ocean, Biogeosciences, 5, 631-656, https://doi.org/10.5194/bg-5-631-2008, 2008.

MPI: Model distribution: https://www.mpimet.mpg.de/en/science/ models/license/, last accessed: 9 October 2018.

Munzar, J.: Alexander von Humboldt and his isotherms, Weather, 22, 360-363, 2012.

Notz, D., Haumann, F. A., Haak, H., Jungclaus, J. H., and Marotzke, J.: Arctic sea-ice evolution as modeled by Max Planck Institute for Meteorology's Earth system model, J. Adv. Model. Earth Syst., 5, 173-194, https://doi.org/10.1002/jame.20016, 2013.

Paulsen, H., Ilyina, T., Six, K., and Stemmler, I.: Incorporating a prognostic representation of marine nitrogen fixers into the global ocean biogeochemical model HAMOCC, J. Adv. Model. Earth Syst., 9, 438-464, https://doi.org/10.1002/2016MS000737, 2017.

Philander, S. G. H., Gu, D., Lambert, G., Li, T., Halpern, D., Lau, N. C., and Pacanowski, R. C.: Why the ITCZ Is Mostly North of the Equator, J. Climate, 9, 2958-2972, 1996.

Rae, J. W. B. and Broecker, W.: What Fraction of the Pacific and Indian Oceans' Deep Water is formed in the North Atlantic?, Biogeosciences Discuss., https://doi.org/10.5194/bg-2018-8, in review, 2018.

Reick, C. H., Raddatz, T., Brovkin, V., and Gayler, V.: Representation of natural and anthropogenic land cover change in MPI-ESM, J. Adv. Model. Earth Syst., 5, 459-482, https://doi.org/10.1002/jame.20022, 2013.

Rodwell, M. J. and Hoskins, B. J.: Monsoons and the dynamics of deserts, Q. J. Roy. Meteorol. Soc., 122, 1385-1404, 1996.

Seager, R., Battisti, D. S., Yin, J., Gordon, N., Naik, N., Clement, A. C., and Cane, M. A.: Is the Gulf Stream responsible for Europe's mild winters?, Q. J. Roy. Meteorol. Soc., 128, 2563-2586, 2002.
Smith, R. S.: The FAMOUS climate model (versions XFXWB and XFHCC): description update to version XDBUA, Geosci. Model Dev., 5, 269-276, https://doi.org/10.5194/gmd-5-2692012, 2012.

Smith, R. S., Gregory, J. M., Thorpe, R. B., and Rodriguez, J.: Response of the meridional overturning circulation in an idealised reverse world experiment, in: EGU General Assembly, session CL26 poster; Ref. No.: EGU2008-A-06893, EGU, 1318 April 2008, Vienna, Austria, 2008.

Sohm, J. A., Webb, E. A., and Capone, D. G.: Emerging patterns of marine nitrogen fixation, Nat. Rev. Microbiol., 9, 499-508, https://doi.org/10.1038/nrmicro2594, 2011.

Stephens, G. L., Juilin, L., Wild, M., Clayson, C. A., Loeb, N. G., Kato, S., L'Ecuyer, T., Stackhouse Jr., P. W., and Andrews, T.: The energy blance of the Earth's climate system, Nat. Geosci., 5, 691-696, 2012.

Stevens, B. and Schwartz, S. E.: Observing and Modeling Earth's Energy Flows, Surv. Geophys., 33, 779-816, 2012.

Stevens, B., Giorgetta, M., Esch, M., Mauritsen, T., Crueger, T., Rast, S., Salzmann, M., Schmidt, H., Bader, J., Block, K., Brokopf, R., Fast, I., Kinne, S., Kornblueh, L., Lohmann, U., Pincus, R., Reichler, T., and Roeckner, E.: Atmospheric component of the MPI-M Earth System Model: ECHAM6, J. Adv. Model. Earth Syst., 5, 146-172, 2013.

Stommel, H.: Thermohaline Convection with Two Stable Regimes of Flow, Tellus, 13, 224-230, https://doi.org/10.1111/j.21533490.1961.tb00079.x, 1961.

Vamborg, F., Brovkin, V., and Claussen, M.: The effect of dynamic background albedo scheme on Sahel/Sahara precipitation during the Mid-Holocene, Clim. Past, 7, 117-131, https://doi.org/10.5194/cp-7-117-2011, 2011.

von Humboldt, A.: Des Lignes Isothermes, Cambridge University Press, Paris, 1817.

Wallace, J. M., Mitchell, T. P., and Deser, C.: The Influence of SeaSurface Temperature on Surface Wind in the Eastern Equatorial Pacific: Seasonal and Interannual Variability, J. Climate, 2, 1492-1499, 1989.

Warren, B. A.: Why is no deep water formed in the North Pacific?, J. Mar. Res., 41, 327-347, https://doi.org/10.1357/002224083788520207, 1983.

WDC Climate: The climate of a retrograde rotating earth (data): https://cera-www.dkrz.de/WDCC/ui/cerasearch/entry? acronym=DKRZ_LTA_110_ds00001, last access: 9 October 2018 .

Zelinka, M. D. and Hartmann, D. L.: Why is longwave cloud feedback positive?, J. Geophys. Res.-Atmos., 115, D16117, https://doi.org/10.1029/2010JD013817, 2010.

Zhou, C., Zelinka, M. D., and Klein, S. A.: Impact of decadal cloud variations on the Earth's energy budget, Nat. Geosci., 9, 871874, https://doi.org/10.1038/ngeo2828, 2016. 